\title{
Analysis and Isolation of Embryonic Mammalian Neurons by Fluorescence-Activated Cell Sorting
}

\author{
Paul A. St. John, Wayne M. Kell, Joann S. Mazzetta, G. David Lange, and Jeffery L. Barker \\ Laboratory of Neurophysiology, NINCDS-NIH, Bethesda, Maryland 20892
}

Cells were dissociated from the CNS of the embryonic mouse and rat to produce cell suspensions suitable for analysis and separation on a fluorescence-activated cell sorter (FACS). Cells from the spinal cord of the embryonic mouse were analyzed in the most detail. Cell suspensions generated three major peaks in histograms of forward-angle light scatter. Examination of material isolated from each peak and labeling of cell suspensions with the nonvital and supravital fluorescent dyes propidium iodide, ethidium bromide, and acridine orange demonstrated that the three peaks represented live cells, dead cells, and subcellular fragments. Passage through the cell sorter did not detectably damage live cells, as shown by light microscopy, FACS analysis, and in vitro culture of sorted cells. Neurons and glial cells collected by sorting survived at least 4 weeks in culture.

Cell suspensions dissociated from the dorsal root ganglia, hippocampus, hypothalamus, cerebellum, and cerebral cortex of the embryonic mouse and from the spinal cord of the embryonic rat produced similar results. Analysis of samples prepared at different developmental stages showed that viable cells could be recovered from each of these regions throughout the important stages of neurogenesis and early cellular differentiation, but that few viable cells could be recovered from animals beyond late embryonic or early postnatal ages.

Quantitative FACS analysis of monoclonal antibody A2B5, tetanus toxin and cholera toxin, and lectins binding to live dissociated cells from the embryonic spinal cord demonstrated that these cells had already developed binding sites for these cellsurface ligands by embryonic day 13 .

These results demonstrate that a fluorescence-activated cell sorter can be used for quantitative analysis of specific cellular properties, that FACS analysis and sorting can be used to identify and isolate live cells from many regions of the embryonic mammalian CNS during important developmental periods, and that sorted neurons and glial cells can be maintained for weeks in culture.

Understanding of cellular development and intercellular interactions in the developing nervous system is a fundamental goal in neurobiology. However, the vast numbers of cell types and the complexity of their interactions can make in vivo studies of cellular mechanisms difficult, if not impossible. The use of tissue culture allows studies at a level of detail usually not possible in vivo. However, most primary cultures contain a mixture of cell types, which usually cannot be distinguished on the basis of morphology, thus making it difficult or impossible to identify

Received Aug. 12, 1985; revised Nov. 14, 1985; accepted Nov. 20, 1985

We wish to thank C. H. Evans for the use of the cell sorter in his laboratory during initial experiments and J. Heinbaugh for technical help on those experiments; J. G. Kenimer and W. H. Habig for the generous gift of antibody to tetanus toxin; and List Laburatories for FITC-conjugated subunit B of cholera toxin.

Correspondence should be addressed to Paul A. St. John, Laboratory of Neurophysiology, NIH-NINCDS, Building 36, Room 2C02, Bethesda, MD 20892.

0270-6474/86/051492-21\$02.00/0 specific cellular phenotypes. Several methods have been developed for identifying or isolating specific cell populations for study in vitro (see reviews by Mirsky, 1982; Schachner, 1982; Schaffner and Schnarr, 1983). One approach with promise involves analysis of cell suspensions using a fluorescence-activated cell sorter (FACS) in combination with specific fluorescent probes.

Cell sorting has been central in the identification and isolation of different cell types in the immune system (see reviews by Kruth, 1982; Loken and Stall, 1982; Loken et al., 1979; Scher and Mage, 1984). Because cells are examined individually, even small subsets of cells, if labeled with fluorescent probes, can be recognized within a heterogeneous population. The sorting capability of the instrument allows the labeled cells to bc isolated for further analysis and maintenance in culture. In studies of the nervous system, this technique has been used to identify different classes of glial cells (Abney et al., 1983; Campbell et al., 1977), to identify and isolate cellular elements from the chick retina (Brackenbury et al., 1984; Derby et al., 1983; Dyer et al., 1983; Rathjen and Gierer, 1981; Rathjen et al., 1981) and presumptive spinal motoneurons from the embryonic chick (Calof and Reichardt, 1984; McPheeters and Okun, 1980), and to analyze cells from the cerebellum of the postnatal mouse (Sack et al., 1983).

We have found that tissue from several major regions of the CNS of the embryonic mouse and rat can be dissociated into cell suspensions that are well suited for analysis and separation by a cell sorter. Cells can be dissociated from all regions examined throughout the important stages of cellular differentiation and histogenesis. The live cells, dead cells, and subcellular fragments in these suspensions can be distinguished simply on the cell sorter, and live cells can be collected by sorting with little or no loss of viability. We have begun to label different classes of cells from the developing mouse spinal cord using a variety of surface-reactive markers whose binding to embryonic neural cells can be detected in the cell sorter. Some of these results have appeared previously in abstract form (St. John and Barker, 1983).

\section{Materials and Methods}

\section{Animals}

Experiments were performed with mice of the Swiss, BALB/C, and C57B16/J strains, and rats of the Sprague-Dawley strain. Pregnancies were timed by counting the day of appearance of a vaginal plug as day 0 . Embryonic mice were staged according to Rugh (1968).

\section{Preparation of dissociated cells}

Cells were prepared from the spinal cord, dorsal root ganglia, hippocampus, hypothalamus, cerebellum, or cerebral cortex. Following dissection, tissue was minced in Puck's buffer (Gibco) containing no $\mathrm{Ca}^{2+}$ or $\mathrm{Mg}^{2+}$ and maintained in this buffer for $30 \mathrm{~min}$ at $37^{\circ} \mathrm{C}$. For enzymatic dissociation, one of the following was included during incubation in Puck's buffer: trypsin $(0.1 \%$, followed by inhibition with excess soybean trypsin inhibitor; Sigma), collagenase ( $0.1 \%$; Worthington), chymotryp- 


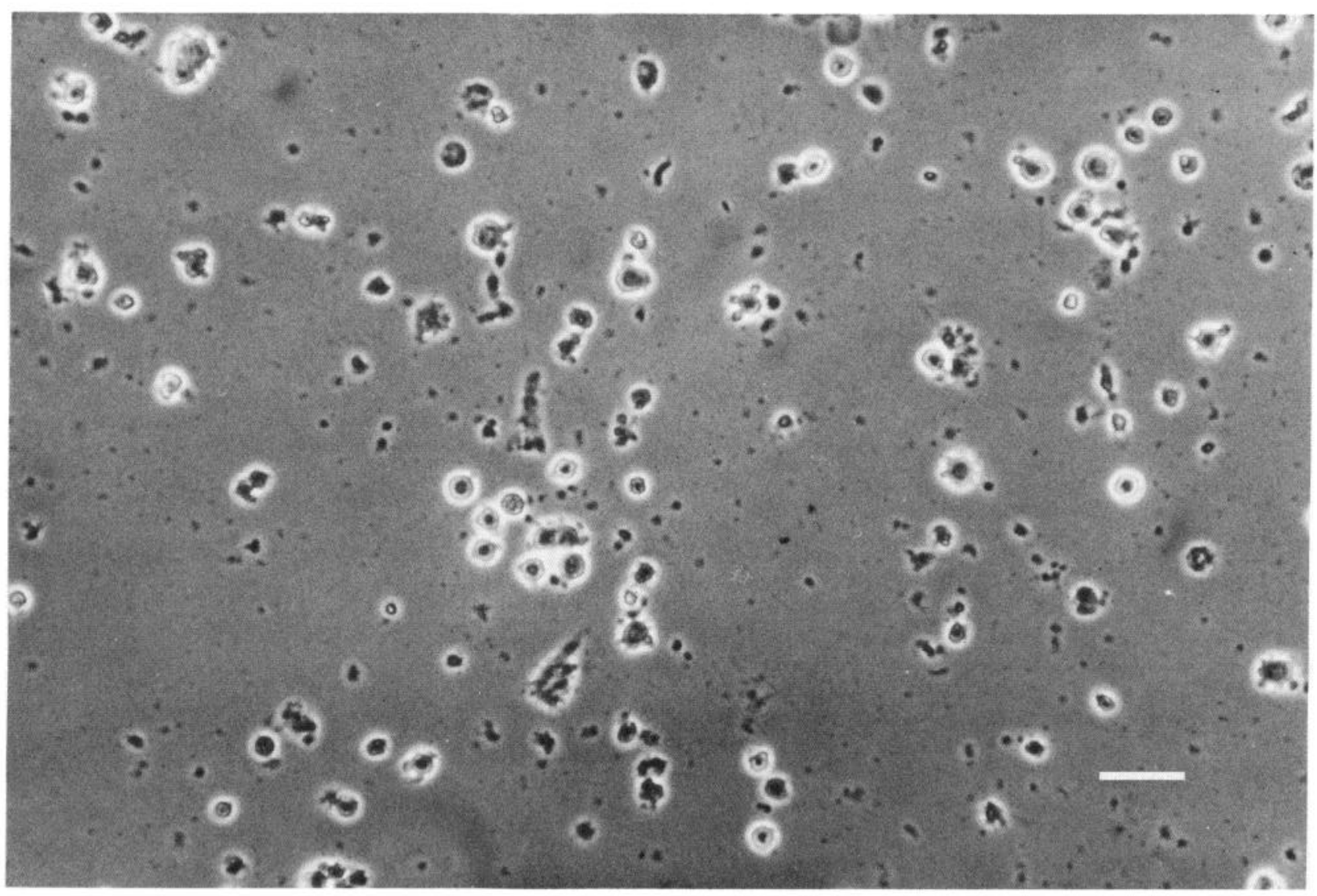

Figure 1. Dissociated cells from spinal cords of embryonic mice at E12.5. Cells were dissociated without the use of enzymes (see Materials and Methods). Note wide range of sizes, presence of both phase-bright and phase-dark elements, and subcellular fragments. Phase-contrast. Bar, $30 \mu \mathrm{m}$.

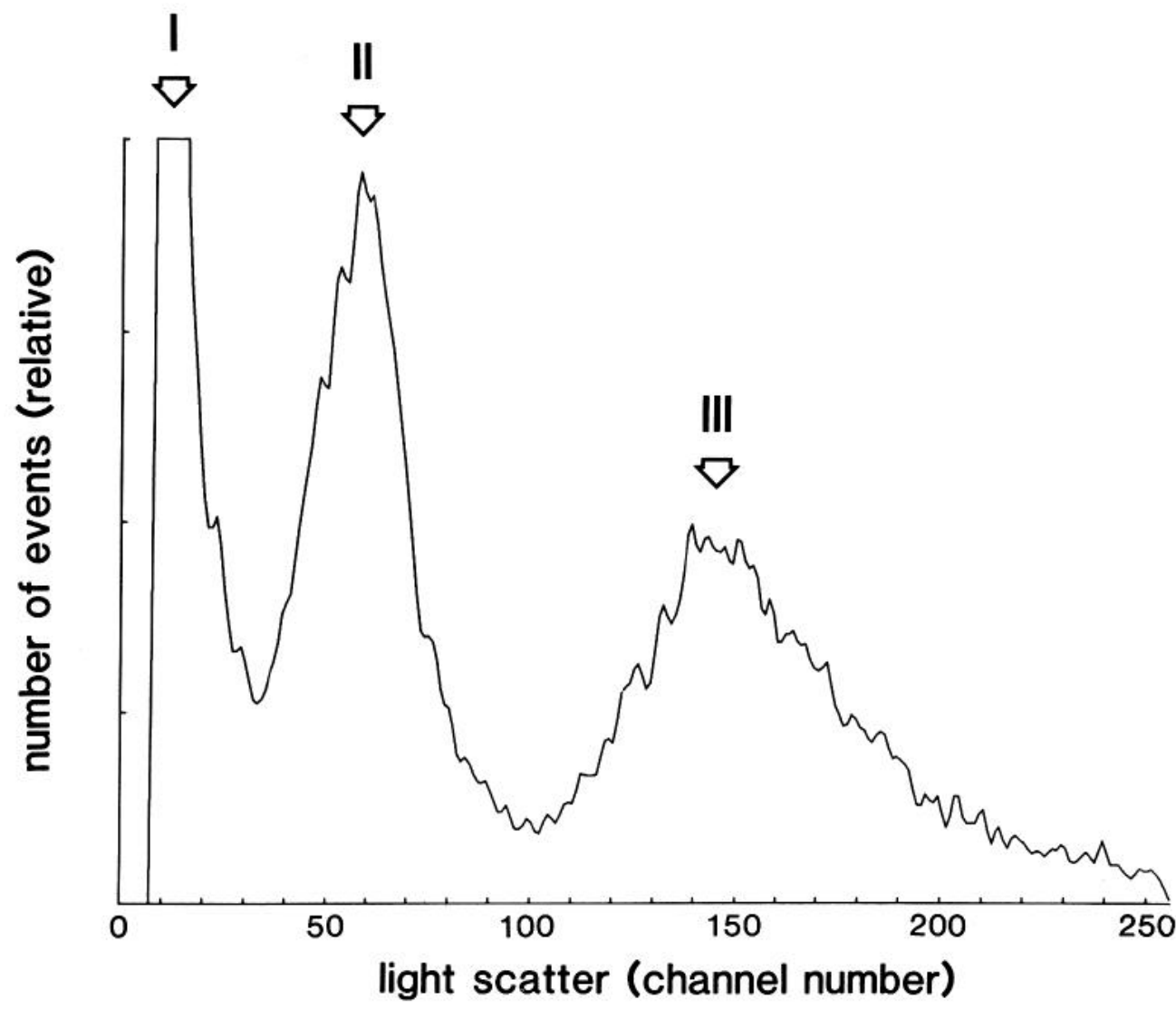

Figure 2. Histogram of light-scatter values for material dissociated from E12.5 spinal cord and analyzed on cell sorter. Positions of three major peaks $(I, I I, I I I)$ are marked. Linear scale on ordinate. 
$\sin (0.1 \%$; Worthington), papain $(0.01 \%$; Sigma), or dispase $(0.1 \%$; Boehringer-Mannheim). Incubation in Puck's buffer with or without enzyme was followed by gentle repeated pipetting to dissociate cells. Following dissociation, cells were centrifuged at $300 \times g$ for $5 \mathrm{~min}$, and the pellet was resuspended in Hank's Balanced Salt Solution (HBSS; Gibco) containing $25 \mathrm{~mm}$ HEPES (Gibco), pH 7.3, and 0.1\% BSA (fraction V; Sigma). An aliquot was analyzed for viability based on exclusion of trypan blue. The suspension was diluted to a density of $1-5 \times 10^{6}$ live cells/ml for cell sorting. In sorting experiments, sorted cells were collected in the buffer used to resuspend the starting sample (HBSS/HEPES/ BSA).

\section{Cell culture}

Cells isolated from the embryonic spinal cord were maintained in vitro according to methods previously described (Barker and Ransom, 1978; Ransom et al., 1977). Cells recovered from cell sorting were centrifuged, and the pellet was resuspended in culture medium (see below). Cells were plated either on collagen- or polylysine-coated tissue culture dishes at a density of $5 \times 10^{4}$ to $1 \times 10^{5}$ cells $/ \mathrm{cm}^{2}$ or on confluent cultures of once-passaged rat cortical astrocytes [prepared by minor modifications of the methods of McCarthy and de Vellis (1980) and Kimelberg (1983)] at a density of $1 \times 10^{3}$ to $1 \times 10^{5}$ cells $/ \mathrm{cm}^{2}$. All cultures were grown in Eagle's Minimal Essential Medium (MEM; Advanced Biotechnologies, Silver Spring, MD) with 5\% horse serum (Hazleton/Dutchland), transferrin $(100 \mu \mathrm{g} / \mathrm{ml}$; Sigma), selenium $(52 \mathrm{ng} / \mathrm{ml}$; Sigma), and insulin $(5$ $\mu \mathrm{g} / \mathrm{ml}$; Collaborative Research, Lexington, MA), and the medium was changed every 3-4 d.

\section{Cell-surface labeling}

Cell suspensions were labeled with the following ligands: monoclonal antibody A2B5 (Eisenbarth et al., 1979; obtained from Pelfreez); monoclonal antibody to Thy 1.2 antigen (Miles); $\mathrm{C}$ fragment of tetanus toxin and monoclonal antibody to tetanus toxin (generous gift from J. G. Kenimer and W. H. Habig, U.S. Food and Drug Administration, Bethesda, MD); FITC-conjugated subunit B of cholera toxin (generous gift from List Biological Laboratories, Campbell, CA); and the lectins wheat germ agglutinin, concanavalin A, Dolichos biflorus agglutinin, peanut agglutinin, Ulex europaeus agglutinin I, Ricinis communis agglutinin I, and soybean agglutinin (Vector Labs). Binding reactions for all ligands were routinely performed at $4^{\circ} \mathrm{C}$, with similar results observed at room temperature and at $37^{\circ} \mathrm{C}$. Hank's BSS containing $25 \mathrm{~mm}$ HEPES, pH 7.3 , and $0.1 \%$ BSA was used for all incubations and washes. Samples were incubated in the ligand for $60 \mathrm{~min}$, then washed. For immunofluorescence, primary antibodies were followed by FITC-conjugated $\mathrm{F}\left(\mathrm{ab}^{\prime}\right)_{2}$ fragments of rat anti-mouse IgG $(\mathrm{H}+\mathrm{L})$, obtained from Jackson Labs and diluted 1:50 for use. Biotin-conjugated lectins were used at final concentrations of $1-2$ and $50-100 \mu \mathrm{g} / \mathrm{ml}$, followed by FITC-conjugated avidin (Vector Labs) at a final concentration of $5 \mu \mathrm{g} / \mathrm{ml}$. For quantitative assays of A2B5 binding, the monoclonal antibody was followed by ${ }^{125} \mathrm{I}-$ $\mathrm{F}\left(\mathrm{ab}^{\prime}\right)_{2}$ fragments of sheep anti-mouse IgG $(\mathrm{H}+\mathrm{L})$, obtained from New England Nuclear and diluted to a final concentration of $1 \mu \mathrm{Ci} / \mathrm{ml}$ (approximately $10 \mu \mathrm{g} / \mathrm{ml}$ ). Incubations in secondary reagents were for 30 $60 \mathrm{~min}$. Cultures labeled with ${ }^{125} \mathrm{I}$-antibodies were dissolved overnight in $1 \mathrm{~N} \mathrm{NaOH}$, and samples were counted in a gamma counter.

Fluorescence microscopy was performed on a Zeiss Photomicroscope III equipped with a $100 \mathrm{~W}$ mercury-arc lamp for epi-illumination. The filter set for FITC included a $450-490 \mathrm{~nm}$ excitation filter, a $510 \mathrm{~nm}$ dichroic mirror, and a $520 \mathrm{~nm}$ long-pass barrier filter (Zeiss filter set 487709 ); the filter set for rhodamine included a $556 / 12 \mathrm{~nm}$ bandpass excitation filter, a $580 \mathrm{~nm}$ dichroic mirror, and a $590 \mathrm{~nm}$ long-pass barrier filter (Zeiss filter set 4877 15). FITC and acridine orange were observed with the FITC filter set; propidium iodide and ethidium bromide, because of their broad excitation and emission spectra, could be observed with either filter set. Samples were observed with a 16 or $25 \times$ oil-immersion Plan-Neofluor objective.

\section{Fluorescence-activated cell sorting (FACS)}

Cell sorting and analysis were performed on a FACS 440 (Becton-Dickinson, Mountain View, CA) equipped with detectors for forward-angle light scatter, right-angle light scatter, and two colors of fluorescence. Excitation was provided by a $4 \mathrm{~W}$ argon ion laser (Spectra Physics) tuned to generate $400 \mathrm{~mW}$ at $488 \mathrm{~nm}$. Emissions from fluorochromes were passed through a $490 \mathrm{~nm}$ long-pass filter, green and red signals were separated by a $570 \mathrm{~nm}$ dichroic mirror, green signals were passed

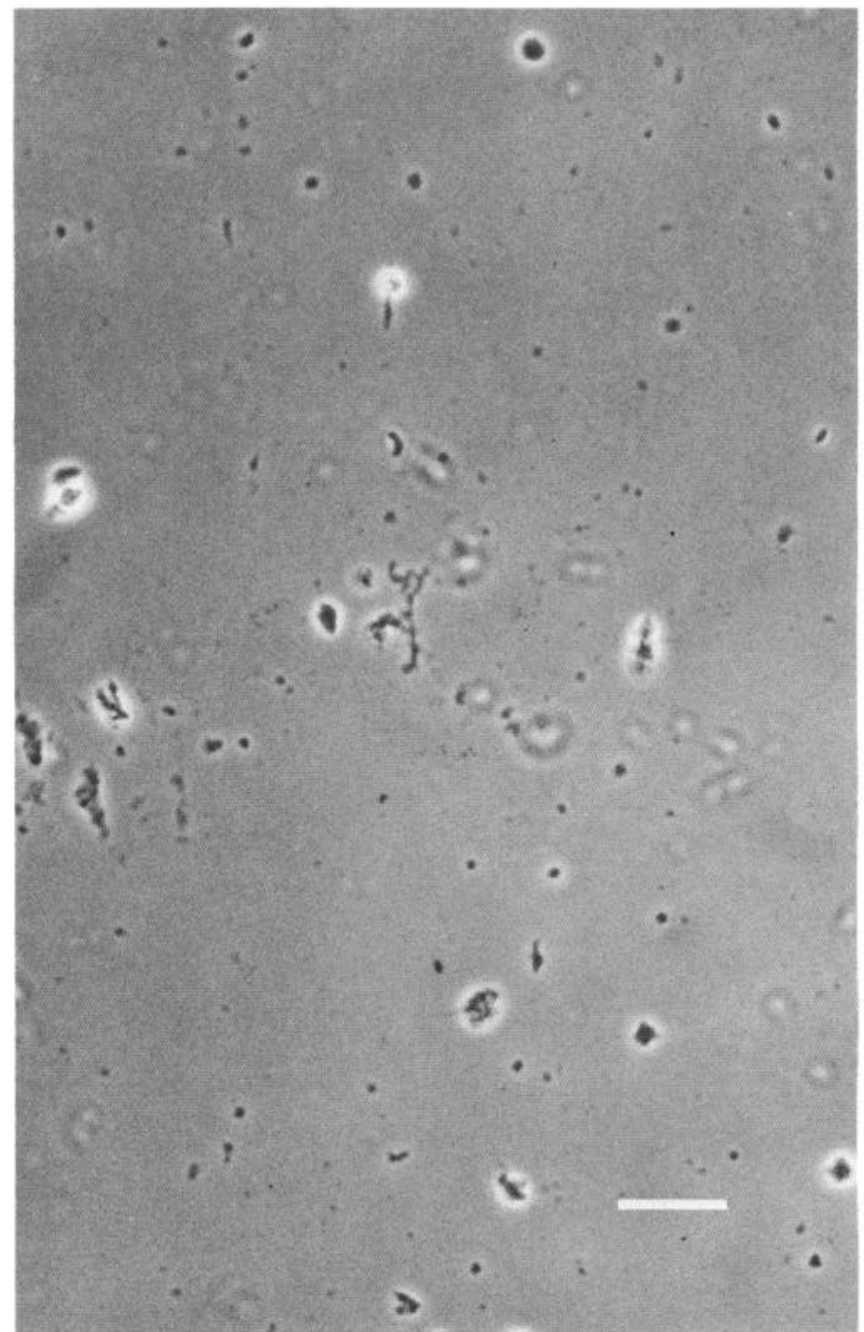

Figure 3. Subcellular fragments recovered from spinal cord (E12.5) cell suspension by sorting material in peak I of the light-scatter histogram. Phase-contrast. Bar, $30 \mu \mathrm{m}$.

through a $530 / 30 \mathrm{~nm}$ bandpass filter, and red signals passed through a $625 / 35 \mathrm{~nm}$ bandpass filter (filters from Becton-Dickinson and Corion). All experiments were performed with $70 \mu \mathrm{m}$ nozzle tips.

All particles with values of light scatter higher than an arbitrarily chosen threshold level were included in the analysis. These particles, called "events" on the cell sorter, included both intact cells and subcellular fragments (see Results). The cell sorter was operated at rates up to 2500 particles/sec for sorting and up to 6000 particles/sec for analysis without sorting. Raw data, usually collected from 50,000 particles per sample, were stored, analyzed, and displayed on a PDP 11/23-based computer (Consort 40; Becton-Dickinson) and a VAX 750 (Digital Equipment Corporation). Data consisted of digitized pulse heights from each of the photosensors of the FACS and were collected to the PDP $11 / 23$ using direct memory access (DMA). The on-line data collection routine was modified from a program supplied by Becton-Dickinson (G. Breitbard, unpublished observations). This program is written in FORTRAN with the necessary assembly language routines for on-line, real-time data acquisition. Further analysis of the data was performed with the same computer or the VAX (operated by the Research Services Branch of NIMH). Programs for analysis were either modified from those supplied by Becton-Dickinson or developed in our laboratory.

When a suspension of cells is passed through a cell sorter, each cell or fragment in the preparation scatters light. The amount of scattered light, a parameter called forward-angle light scatter, is quantified, and the results for the light-scattering properties of the population are expressed as a frequency histogram displaying the number of particles or events as a function of the light scattered. Intensities of fluorescence for 

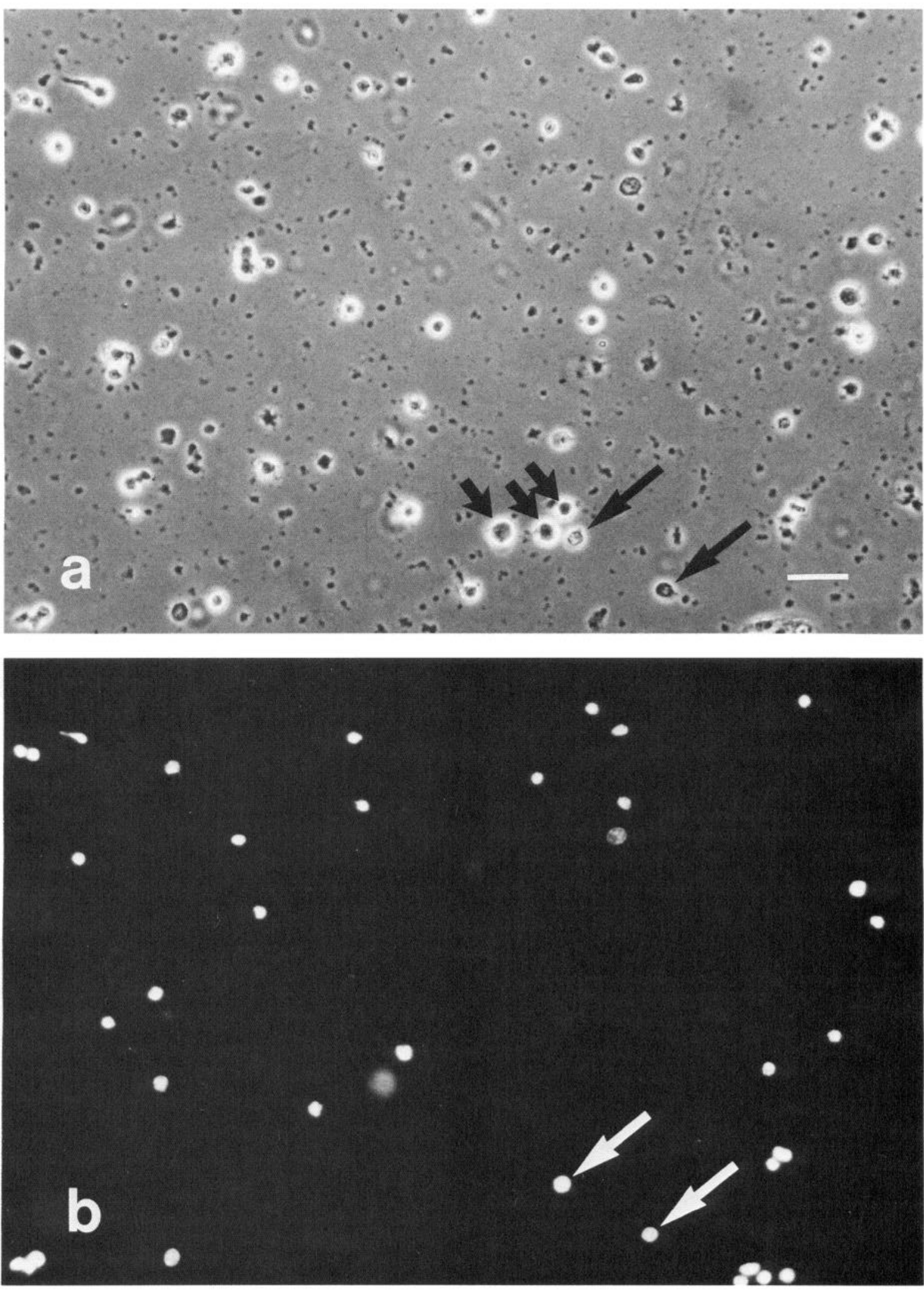

Figure 4. Propidium iodide (PI) staining of dissociated cells from E13 spinal cord. Cells were dissociated without enzymes and then stained with PI as described in Materials and Methods. $a$, Phase-contrast; $b$, fluorescence view of same field: FITC filter set. Brightly fluorescent PI-positive cells are easily distinguished from nonfluorescent PI-negative cells. PI-negative cells (short-tailed arrows in $a$ only) usually were phase-bright, while PI-positive cells (long-tailed arrows) usually were more phase-dark. Bar, $30 \mu \mathrm{m}$. 


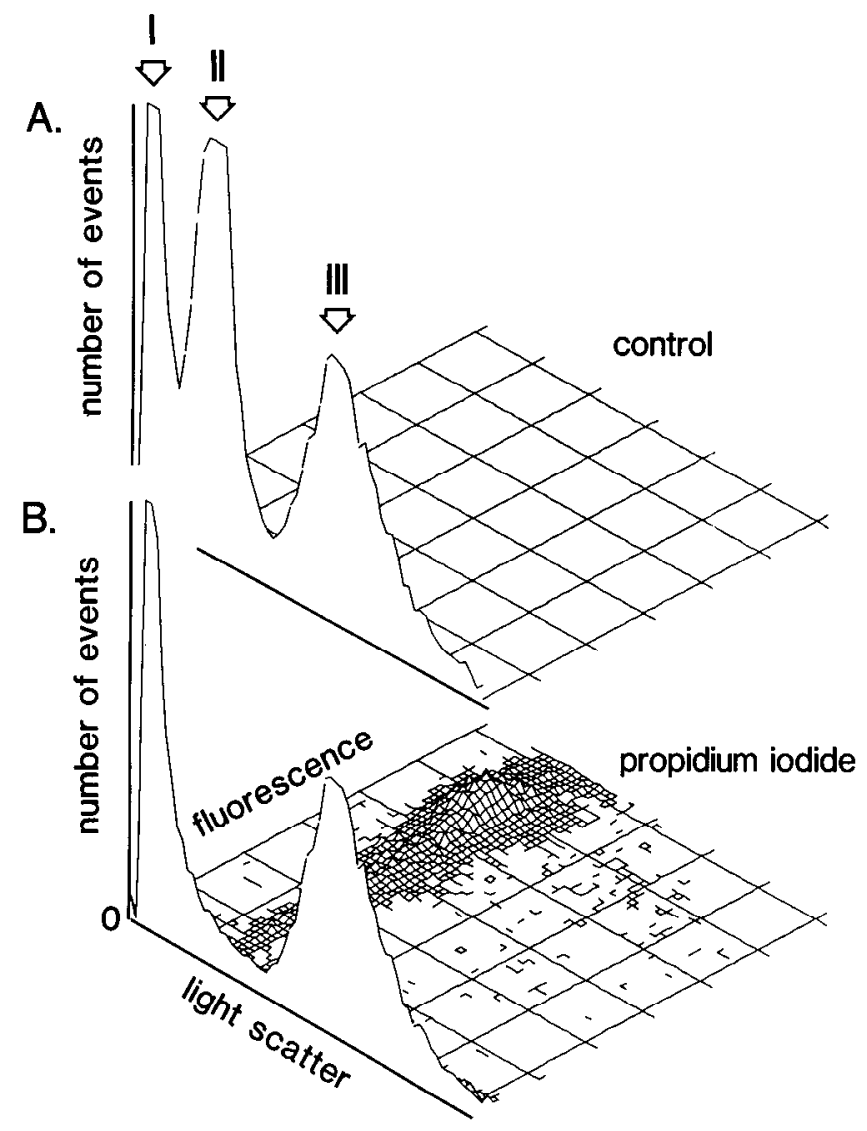

Figure 5. FACS analysis of propidium iodide (PI) staining of material dissociated from E13 spinal cords. Dual-parameter hidden-line histograms of light scatter and fluorescence for material dissociated without enzymes are shown. $A$, Untreated control sample displays little, if any, background fluorescence. The three major peaks of light scatter $(I, I I$, $I I I)$ are seen in lowest channels of fluorescence (foreground). B. Sample stained with PI displays fluorescence in almost all material that comprises peak II but in almost no cells whose light scatter falls in peak III. Vertical axis, representing relative number of events in each channel, is on a linear scale.

the cells and particles in a sample also are displayed as frequency histograms. Data often are expressed as dual-parameter histograms displaying the distribution of the cells according to any two measured parameters. Provisions were made to plot values of the parameters as a function of the cells" position in the sort, which was an indication of the value of the parameter as a function of time. This was used to check for variations due to large-scale inhomogeneity in samples.

Propidium iodide (Sigma) was added to samples at a final concentration of $75 \mu \mathrm{M}(50 \mu \mathrm{g} / \mathrm{ml})$ to label the dead cells in the population (e.g., Jacobs and Pipho, 1983; Krishan, 1975; Loken and Stall, 1982). Ethidium bromide ( $25 \mu \mathrm{M}$; Sigma) and acridine orange ( $8 \mu \mathrm{M}$; Sigma) were used to label dead and live cells, respectively, as described by Parks et al. (1979); there was virtually no spillover between channels for the signals from these dyes.

Samples in a given group (e.g., in a given figure) were analyzed at the same time with the settings on the instrument unchanged between samples. Samples from different groups (e.g., from different regions of the CNS) were analyzed with similar, but not necessarily identical settings. Thus, results for samples from different regions of the CNS, although similar, are not strictly comparable, for example, with respect to exact positions of peaks in histograms.

\section{Results}

\section{Spinal cord and dorsal root ganglia}

Spinal cord

Material dissociated from the spinal cords of mice at embryonic day 12.5 (E12.5), the age normally used to establish cell cultures
Table 1. Comparison of staining by trypan blue and propidium iodide

\begin{tabular}{lcc} 
& TB positive & TB negative \\
\hline PI positive & $168(46.3 \%)$ & $1(0.3 \%)$ \\
PI negative & $1(0.3 \%)$ & $193(53.2 \%)$
\end{tabular}

A sample of dissociated cells from embryonic spinal cords (E13) was stained by both trypan blue (TB) and propidium iodide (PI), and cells in randomly chosen fields were examined and counted by bright-field and fluorescence microscopy.

(e.g., Ransom et al., 1977), is shown in Figure 1. Although axons and dendrites have already begun to develop in vivo at E12.5 (Flanagan, 1969; Holley et al., 1982a-c; Lance-Jones, 1982; Wentworth, 1984a, b), most were sheared off during dissociation, leaving only cell bodies and subcellular fragments.

The histogram of light scatter for material dissociated from spinal cords at E12.5 consistently displayed three major peaks (Fig. 2). Several approaches were used to identify the cellular components constituting each peak.

\section{Peak I}

Material recovered by sorting peak I consisted of subcellular fragments and debris (Fig. 3). Two complementary observations suggested that the cellular debris and fragments recovered by sorting from peak I were those present in the starting sample rather than new fragments generated from intact cells during passage through the cell sorter. Cell suspensions centrifuged through a density gradient to remove debris prior to analysis on the cell sorter generated a smaller peak I. Cell suspensions that contained more debris, such as those severely triturated or subjected to osmotic shock, generated a larger peak I (not shown).

\section{Peaks II and III}

Several lines of evidence showed that peak II was generated by dead cells, while peak III was comprised of live cells. There was close correspondence between the percentages of trypan bluestained and unstained cells in a sample and the relative numbers of cellular elements scattering light in peaks II and III. Physical methods that disrupt cells, such as osmotic shock or incubation with cytotoxic concentrations of lectins, consistently decreased the size of peak III and stoichiometrically increased the size of pcak II (not shown).

Direct evidence that peak II corresponds to dead cells and peak III to live cells came from analysis of cell suspensions stained with nonvital and vital fluorescent dyes. Propidium iodide (PI), a 668-Da fluorescent dye excluded from live cells but taken up by dead cells (Krishan, 1975; Loken and Stall, 1982), labeled cells that appeared relatively dark and flat in phasecontrast and did not stain phase-bright, apparently spherical cells (Fig. 4). There was a close correspondence between staining by PI and staining by trypan blue. In samples stained with both dyes, virtually every cell stained by one dye was also stained by the other (Table 1). Among samples prepared from the spinal cord by different methods of dissociation, there was a significant correlation between the exclusion of trypan blue determined microscopically and exclusion of PI determined on the cell sorter (Table 3). This correspondence between trypan blue and PI staining was seen consistently in samples from different embryonic periods and from different regions of the developing CNS. I hus, PI fluorescence was considered functionally equivalent to trypan blue as a marker of nonviable cells in these dissociated cell suspensions.

Analysis on the cell sorter of cells dissociated from embryonic spinal cord and stained with PI revealed that over $80 \%$ of the cells comprising peak II were labeled, while over $90 \%$ of the cells in peak III were not (Fig. 5). On the basis of staining with 

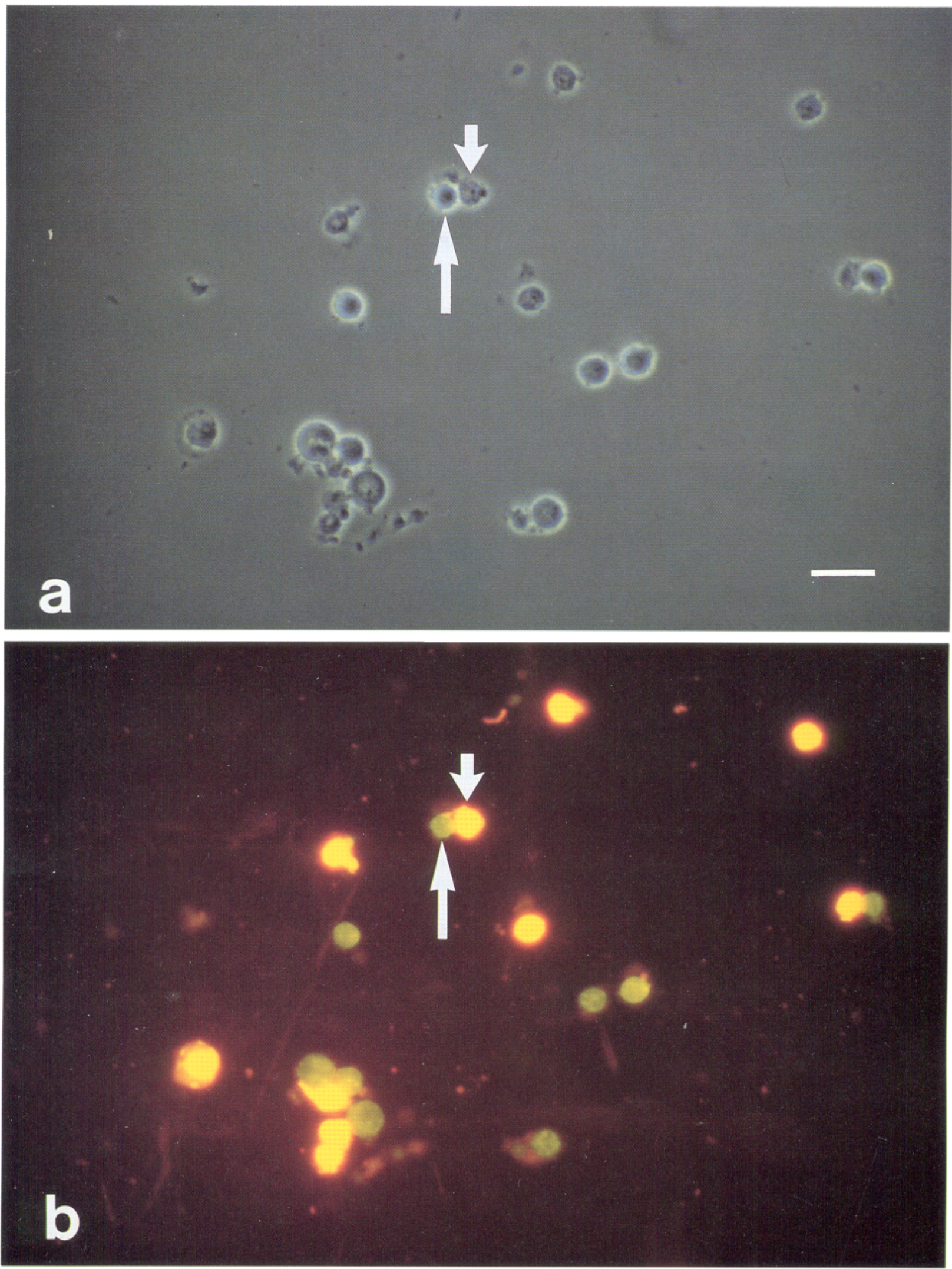

Figure 6. Acridine orange (AO) and ethidium bromide (EB) staining of dissociated cells from E13 spinal cord. Cells were dissociated without enzymes and were stained with AO and EB as described in Materials and Methods. $a$, Phase-contrast; $b$, fluorescence view of same field: FITC filter set. AO-positive cells (long-tailed arrow) fluoresce green and usually are phase-bright, while EB-positive cells (short-tailed arrow) fluoresce yellow/red and usually are more phase-dark. Bar, $30 \mu \mathrm{m}$. 

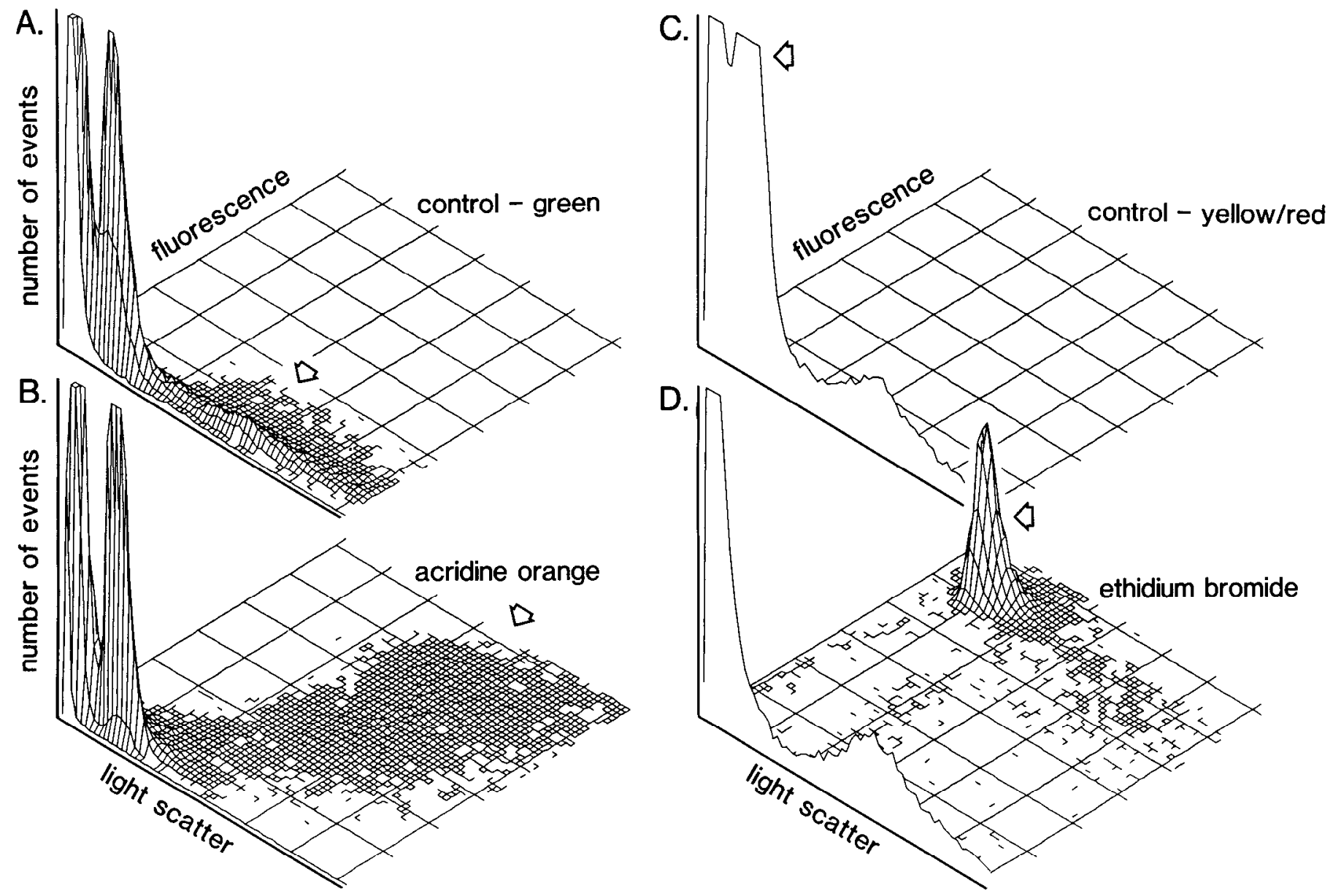

Figure 7. FACS analysis of acridine orange (AO) and ethidium bromide (EB) staining. Figure shows dual-parameter histograms of light scatter and fluorescence for material dissociated without enzymes from E13 spinal cords. $A$ and $C$, Unstained control cells. $B$ and $D$, Cells stained with $\mathrm{AO}$ and EB. Control sample displays little or no green fluorescence $(A)$ or yellow/red fluorescence $(C)$. Sample stained with AO and EB displays green fluorescence from $A O(B)$ in almost all cells with light scatter in peak III (arrows in $A$ and $B$ ) but in almost no cells in peak II; yellow/red fluorescence from EB $(D)$ is found in most cells of peak II (arrows in $C$ and $D$ ) but in few cells in peak III. Linear scale on vertical axes.

PI, then, pcak II was comprised largely of nonviable cells and peak III was composed mostly of live cells. The same finding was made for cells dissociated from several supraspinal regions of the CNS (see below).

Cell suspensions from the spinal cord were stained with two other fluorescent dyes, acridine orange $(\Lambda \mathrm{O})$ and ethidium bromide (EB), that label vital and nonvital cells, respectively (Parks et al., 1979). Because their fluorescent emissions occur at different wavelengths, these dyes could be used simultaneously to label vital and nonvital cells for analysis on a a fluorescence microscope (Fig. 6) or on the cell sorter (Fig. 7). In the example shown in Figure 7, quantitative analysis showed that EB labeled $15 \%$ of all particles; the light-scatter histogram for these particles contained a single peak coincident with peak II for the starting material. AO labeled $49 \%$ of all particles, and these generated a light-scatter histogram with a single peak coincident with peak III of the starting sample. Thirty-seven percent of all particles were not stained by either dye, and these comprised peak I in light scatter. Less than $1 \%$ of all particles were labeled by both $\mathrm{AO}$ and $\mathrm{EB}$; these few particles were spread uniformly across the entire range of light scatter. By these criteria, then, about $64 \%$ (percentage of $\mathrm{EB}$-positive plus percentage of $\mathrm{AO}$-positive) of all particles in the suspension taken for illustration were cell bodies, and about three-quarters of these (AO-positive) were viable. Thus, analysis with $\mathrm{EB}$ and $\mathrm{AO}$ provided further evi- dence that peak II contained mostly nonvital cells and peak III primarily vital cells.

Additional characterization of the material in peaks II and III was obtained by microscopic examination of the material sorted according to either light scatter alone in unstained samples or both fluorescence and light scatter in samples stained by PI. When PI-positive cells were sorted, virtually all of them could be stained by PI (Fig. 8) or trypan blue after the sort. Sorted PI-positive cells did not survive in culture, even under conditions that supported survival of live cells at a 50-fold lower plating density. The nonviability of PI-positive cells was not simply a toxic effect of the dye, since cells with peak II levels of light scatter sorted from an unstained sample also took up trypan blue after the sort and failed to survive in culture (Table 2 ); less than $2 \%$ of unstained cells in peak II were viable in cultures.

Cells that had peak III levels of light scatter and excluded PI, when isolated by cell sorting, consistently were found to be phase-bright (Fig. 9a). When such cells were restained with PI, almost all were found still to exclude the dye (Fig. 9b). Quantitative analysis on the cell sorter showed that over $90 \%$ of them still excluded PI (not shown). Unlike the material isolated from peak II, most cells sorted from peak III survived in culture for at least $4 \mathrm{~d}$ (Table 2) to 1 week (Fig. 10), and many survived for more than 4 weeks, similar to the survival of unsorted cells 

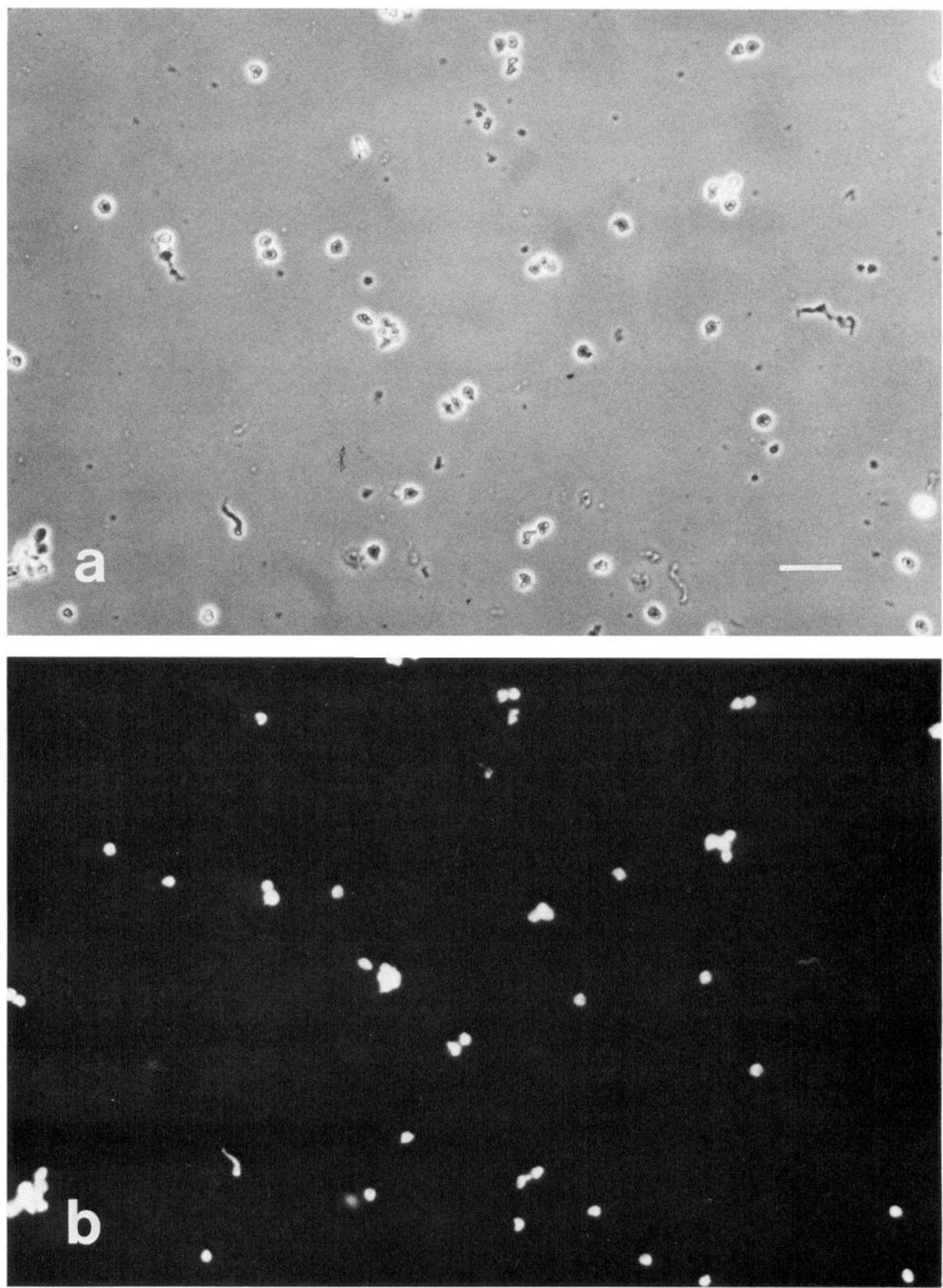

Figure 8. Sorted PI-labeled cells. Cells were dissociated without enzymes from E13 spinal cords and stained with PI. Cells labeled by PI were isolated by sorting and stained with fresh PI before microscopy. $a$, Phase-contrast; $b$, fluorescence of the same field. Note that almost all cells stained with PI. Bar, $30 \mu \mathrm{m}$. Another, unstained portion of the same starting sample was used for sorting the cells shown in Figure 9.

in culture. The fact that few PI-negative cells became PI-positive during sorting and the fact that many sorted cells survived for weeks in culture after sorting demonstrated that most of the live cells in a given sample were not detectably damaged by cell sorting per se. Cells that survived in culture included many that displayed neuronal morphology (Fig. 10) and could be labeled by antibody to neurofilament and others that could be labeled by antibody to glial fibrillary acidic protein (P. A. St. John, 

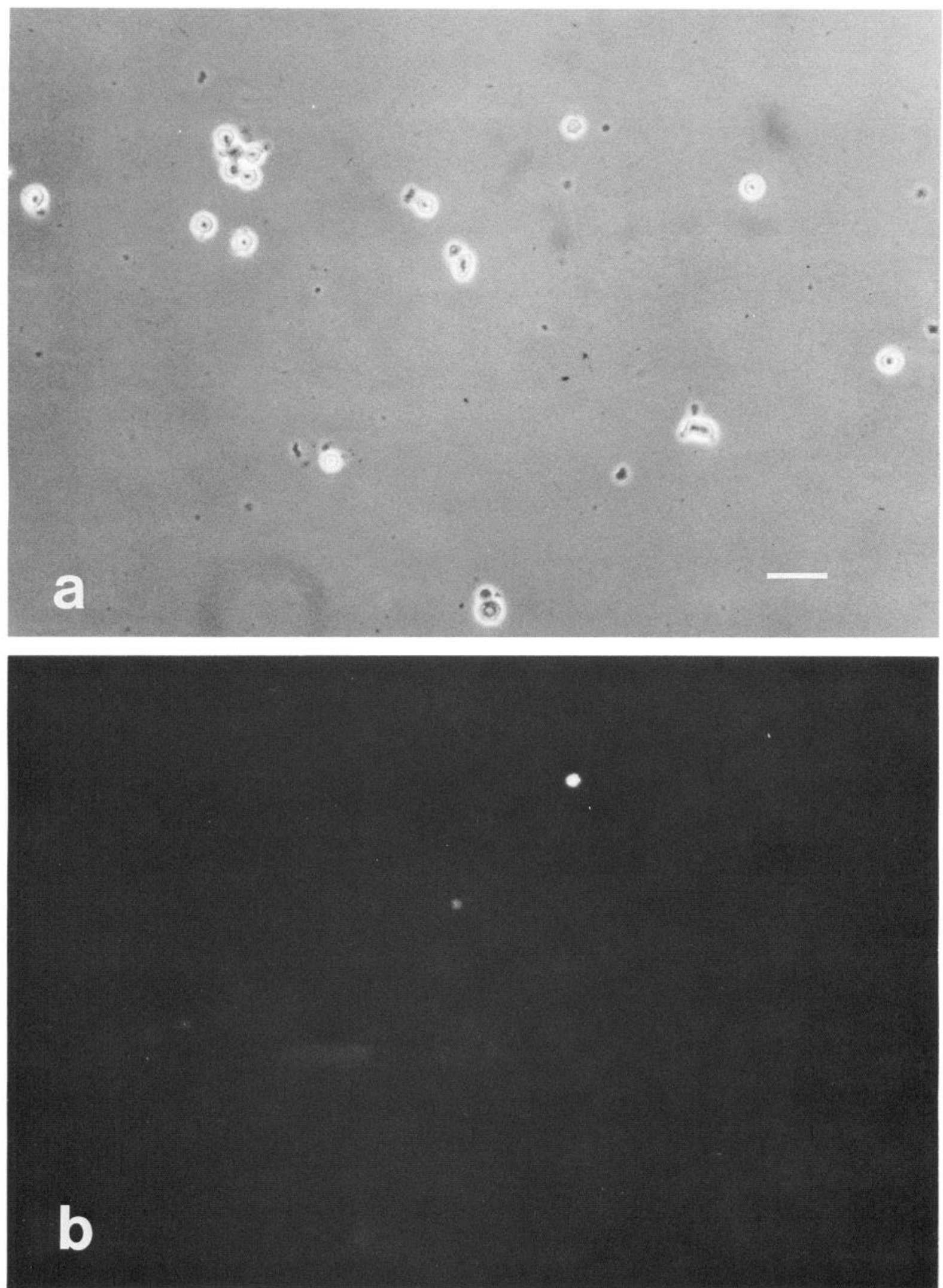

Figure 9. Sorted cells from peak III of light scatter. Cells dissociated without enzymes from E13 spinal cords (same sample as used for sorting propidium iodide-labeled cells shown in Fig. 8) were prepared without staining and were sorted on the basis of light scatter alone. Cells with light scatter in peak III were collected and stained after the sort with PI before microscopy. $a$, Phase-contrast; $b$, fluorescence of the same field, FITC filter set. Almost no cells stained with PI after being sorted. Bar, $30 \mu \mathrm{m}$. 


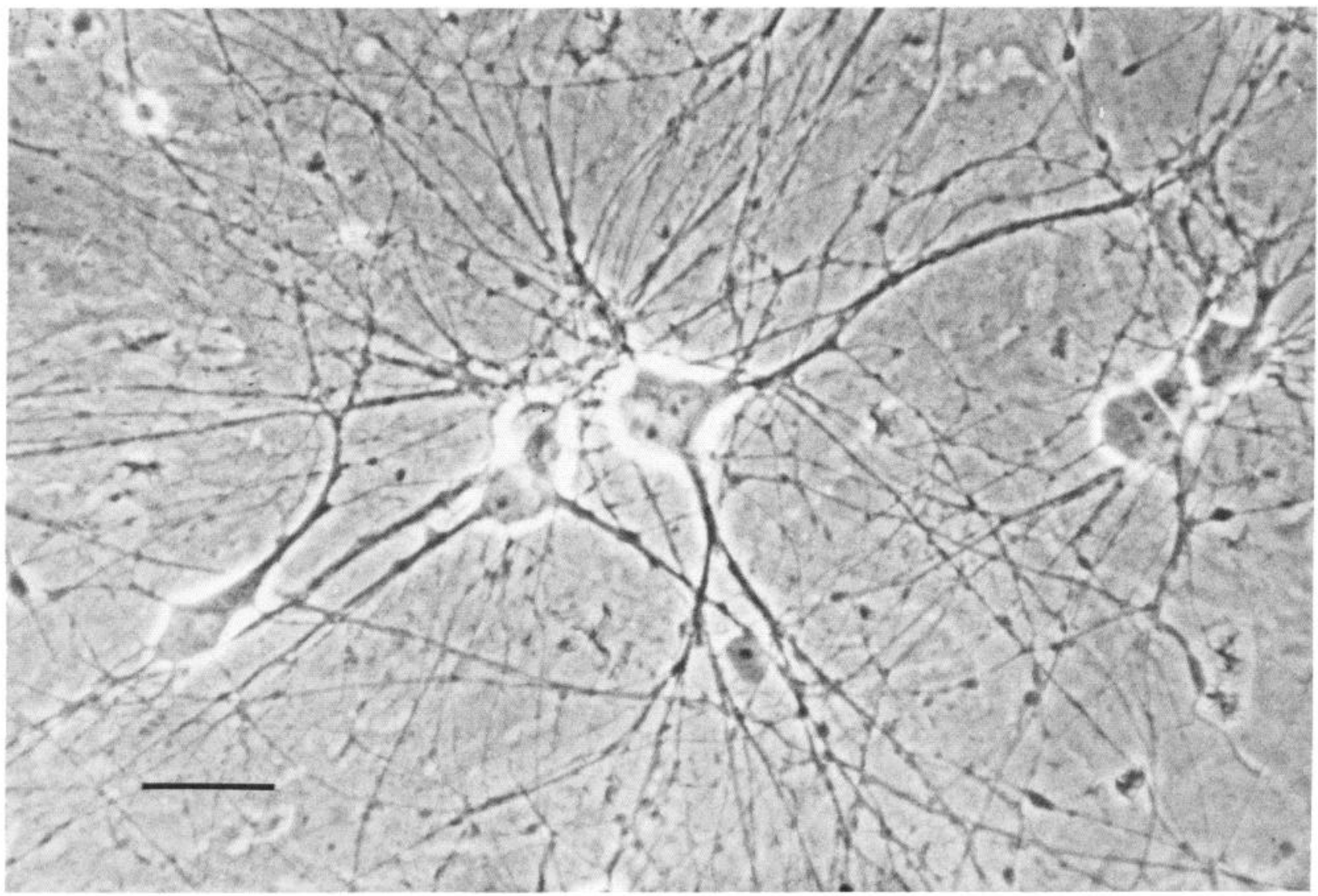

Figure 10. Sorted cells in culture. Dissociated cells with light scatter in peak III were isolated by sorting and maintained in culture for $7 \mathrm{~d}$ on a previously plated layer of cortical astrocytes (see Materials and Methods). Sorted cells are those with large, phase-bright cell bodies (arrows) and extensive processes; flat, phase-dark cells are part of astrocyte culture. Over $90 \%$ of such sorted cells exclude PI or EB and take up AO in culture. Sorted cells plated directly on coated culture dishes produced comparable results. Phase-contrast. Bar, $30 \mu \mathrm{m}$.

unpublished observations). The apparent presence of these proteins that mark differentiated neurons and astrocytes, respectively, suggests that differentiation of these major classes of neural cells in vitro may proceed normally after sorting, in agreement with previous studies of sorted glial cells (e.g., Abney et al., 1983).

\section{Table 2. Survival of sorted cells in culture}

\begin{tabular}{lrrc} 
Sample & $\begin{array}{l}\text { Number } \\
\text { plated }\end{array}$ & $\begin{array}{l}\text { Number at } \\
3 \mathrm{~d}^{b}\end{array}$ & $\begin{array}{l}\text { Survival } \\
(\%)\end{array}$ \\
\hline Peak II of & 50,000 & 0 & $<2^{c}$ \\
light scatter & 100,000 & 0 & $<1^{c}$ \\
& 500,000 & 7500 & 1.5 \\
Peak III of & 50,000 & 67,500 & 135 \\
light scatter & 100,000 & 120,000 & 120 \\
& 500,000 & 239,000 & 48
\end{tabular}

Nominal number of cells based on the number of particles sorted, as counted by the instrument during sorting; this number was not confirmed with a hemocytometer. Samples were plated on confluent cultures of cortical astrocytes in $35 \mathrm{~mm}$ dishes (see Materials and Methods).

${ }^{b}$ Number of sorted cells surviving at $3 \mathrm{~d}$ was estimated by binding of monoclonal antibody A2B5 and radioactive secondary antibody (see Materials and Methods). A standard curve was generated with unsorted cells from a different aliquot of the same cell suspension that was used for sorting. The nominal number of cells surviving in the sorted samples was estimated by comparison with the standard curve.

${ }^{c}$ Indicated percentages correspond to limits of detection for antibody binding.

\section{Variability and reproducibility}

Before using the cell sorter to analyze differences between histograms for different samples, it was necessary to assess the variability among replicate samples prepared by the same procedure. This was done with individual spinal cords from five embryonic mice that were selected as being at the same developmental stage (E12). Each spinal cord was hemisected, one half was dissociated with trypsin, and the other half was dissociated nonenzymatically. Nonenzymatic dissociations consistently produced histograms of light scatter with three characteristic peaks whose positions and relative sizes were quite similar from sample to sample (Fig. 11). The results demonstrated that variation was low among replicate samples prepared from different animals of the same age.

\section{Dependence on method of dissociation}

Several methods for enzymatically dissociating cells from the embryonic spinal cord were compared with nonenzymatic dissociation to develop a protocol for the optimal yield of live cells. Spinal cords of mice at approximately E13 were dissociated with trypsin, chymotrypsin, collagenase, or dispase, and the cell suspensions were analyzed on the cell sorter. Each enzyme produced a suspension with a higher fraction of live cells than was produced by simple mechanical dissociation, as shown by exclusion of trypan blue (Table 3 ) and by light scatter and PI labeling analyzed on the cell sorter (Table 3, Fig. 12). However, dissociation protocols that produced a high fraction of viable cells did not invariably produce a high total number of viable 


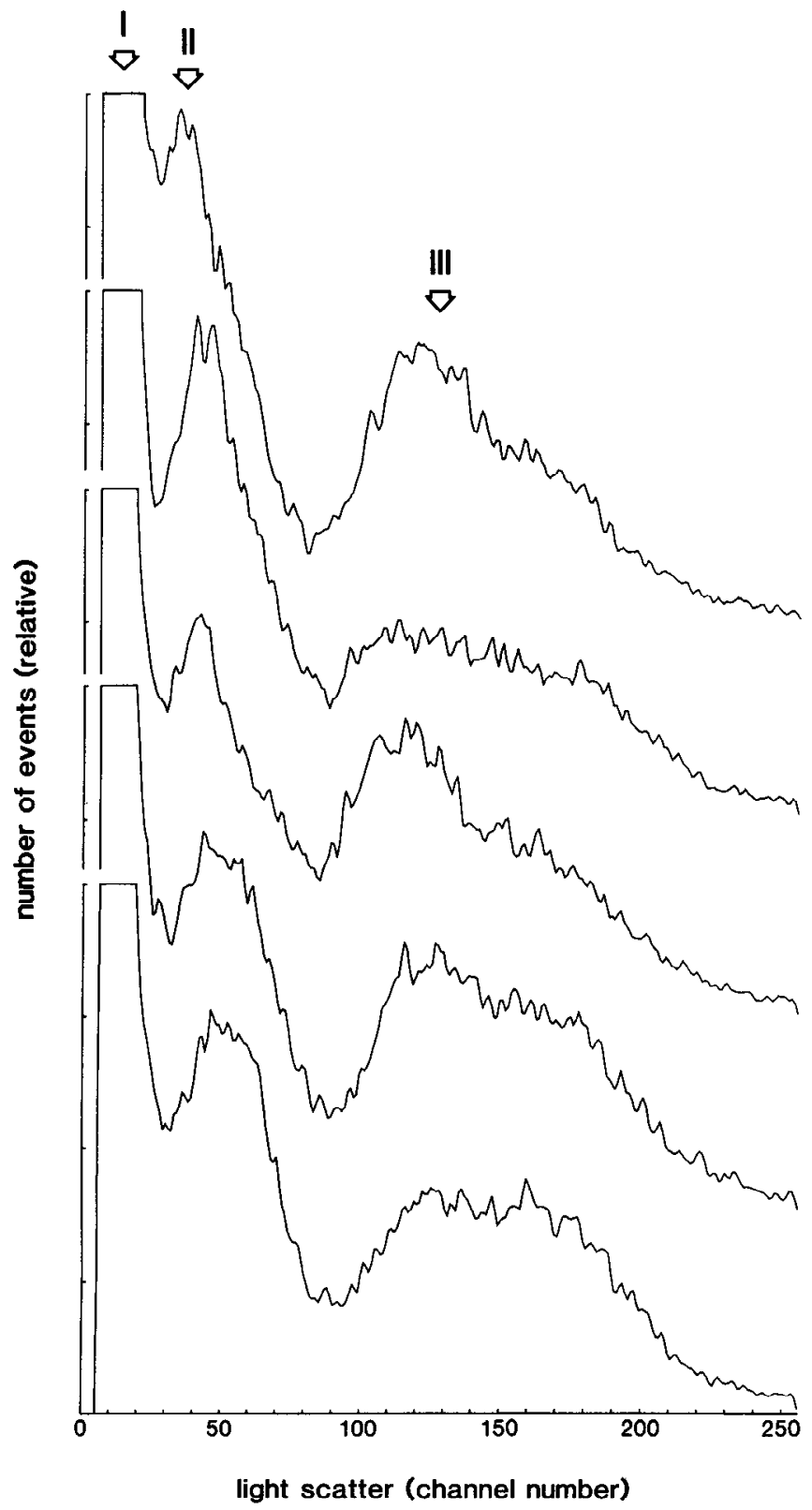

Figure 11. Variation among samples of dissociated cells analyzed on the cell sorter. Spinal cords from individual embryos, all at E12.5, were dissociated without enzymes, stained with PI to mark dead cells and analyzed separately on the cell sorter. Results are displayed as histograms of values for light scatter. Note similarity of positions and relative areas under the peak for major peaks (II and $I I I)$ among different samples; staining with PI (not shown) confirmed that peak II contained the PI-positive cells.

cells per spinal cord. For example, over $95 \%$ of the cells in samples dissociated with dispase had light scatter in peak III and excluded PI, but the total yield of such viable cells per spinal cord was relatively low (Table 3 ). Protocols using trypsin or collagenase both produced high fractions of live cells and high total yields, but results with trypsin were more consistent among different lots of enzyme, so trypsin was used for routinc enzymatic digestion in further experiments.

Figure 12. FACS analysis of dissociation methods. Spinal cords from embryos at E13 were dissociated by the methods indicated (details in Materials and Methods), stained with PI, and analyzed on the cell sorter. Histograms for light scatter are displayed. Sample labeled trypsin +

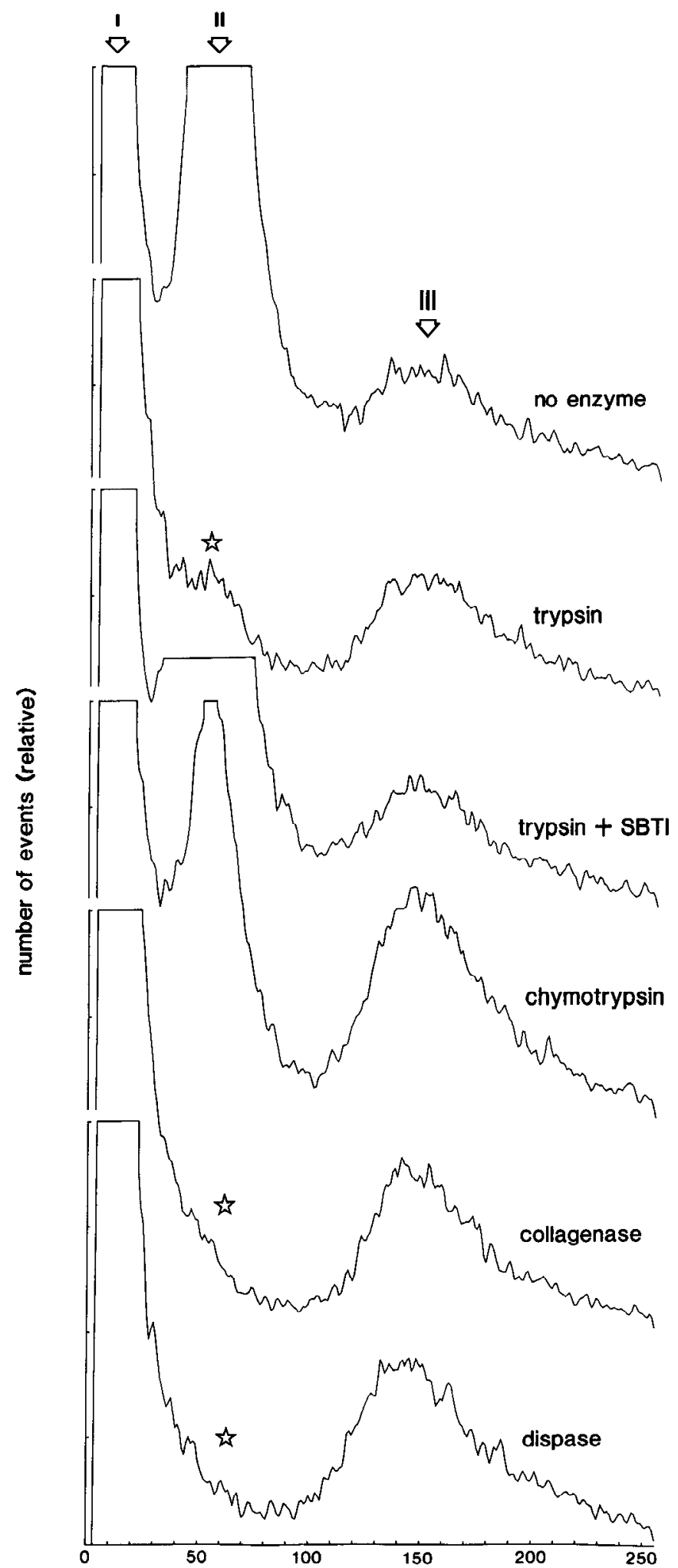

$S B T I$ was prepared with trypsin that was mixed with soybean trypsin inhibitor before use to inactivate the trypsin. Note differences in relative sizes of major peaks (II and $I I I)$ between samples prepared with and without enzymes, with almost no peak II (star) for samples prepared with trypsin, collagenase, and dispase; peak II in the sample prepared with SBTI-inhibited trypsin was comparable to that in the sample prepared with no enzyme but was truncated for display. Staining with PI (not shown) confirmed that peak II contained the PI-positive cells in all samples. Quantitative analysis of these samples is presented in Table 3 . 


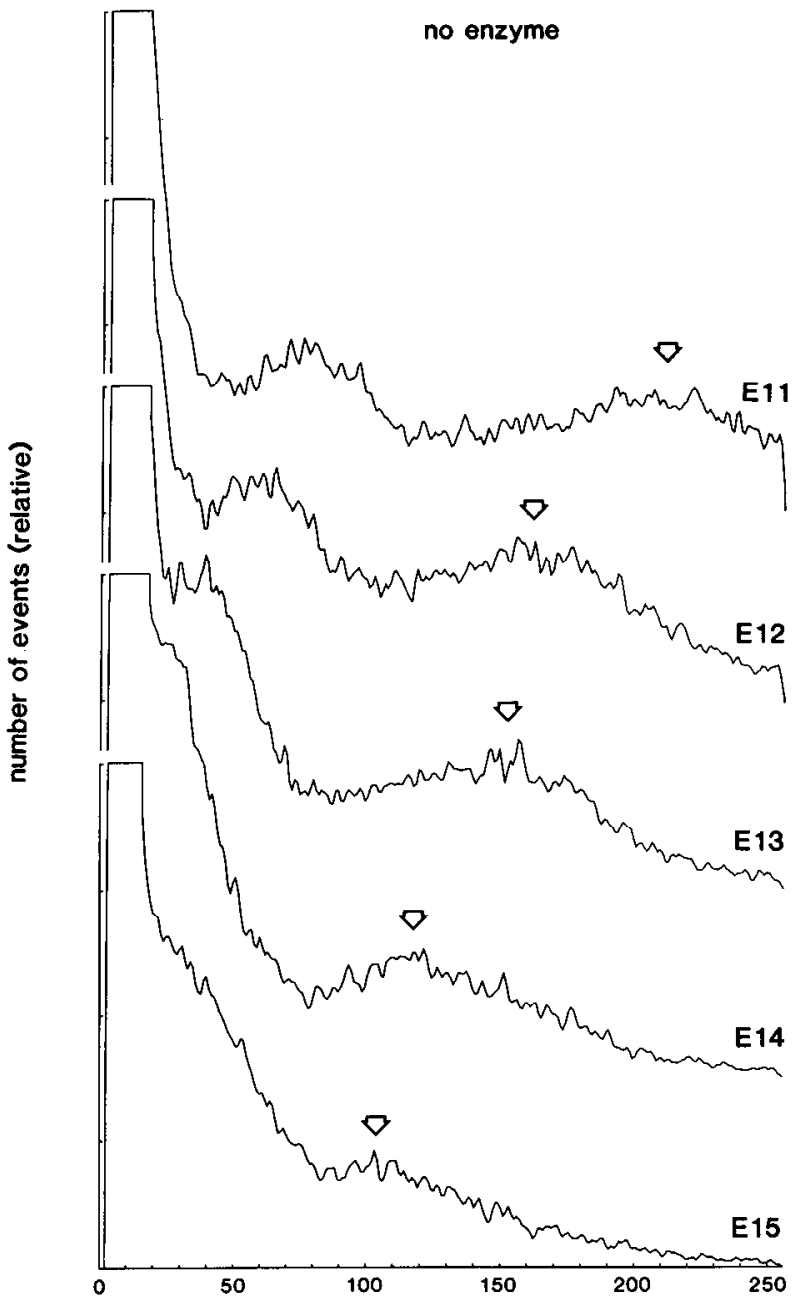

light scatter (channel number)

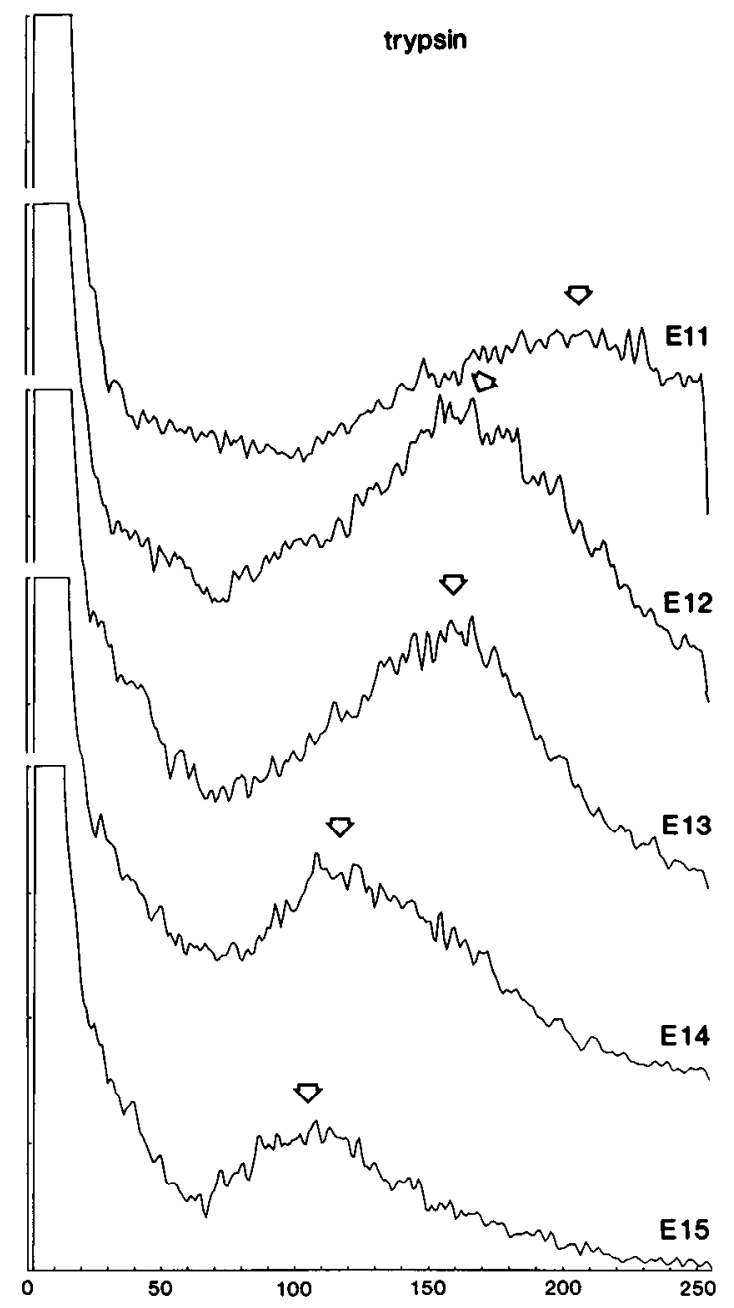

light scatter (channel number)

Figure 13. FACS analysis of material dissociated from spinal cords of mice at E11, E12, E13, E14, and E15. Spinal cords from individual embryos at the indicated ages were hemisected, and half were dissociated with trypsin and the other half dissociated without enzymes. The samples were stained with PI before analysis on the cell sorter. Histograms for light scatter alone are displayed. Note changes in relative sizes and relative positions of peaks III (arrows) and II at different ages (much of peak III was off scale in samples from E11). Staining with PI (not shown) confirmed that peak II contained the PI-positive cells in all samples.

\section{Dependence on age}

The effect of age on the yield of live dissociated cells was examined with nonenzymatic and tryptic dissociation of spinal cords from mice at ages E10-E15. Although many live cells could be recovered from the spinal cord at E10, E11 was the earliest age when the spinal cord could routinely be dissected free of other tissue. Both mechanical and enzymatic dissociation of this early embryonic tissue yielded many live cells (Fig. 13). The total number of live cells recovered per spinal cord, as determined by hemocytometer, increased with embryonic age to a peak at E12-E13. The number of cells killed during nonenzymatic dissociation also increascd with agc (notc the increasingly large peaks I and II for samples from animals of increasing ages). Through E13, this loss could largely be overcome by using trypsin for dissociation, as shown by the large peak III in the light-scatter patterns (Fig. 13: E11, E12, E13, and E14).

In suspensions dissociated from later embryonic ages $(\mathrm{E} 17$ or later), virtually no viable cells could be dissociated from the spinal cord by use of trypsin or any of the other enzymes examined. Attempts to dissociate live cells from the spinal cords of neonatal animals or adults were uniformly unsuccessful. Thus, examination of live cells from the mouse spinal cord on the cell sorter indicates that viable cells can be analyzed and sorted throughout the period E11-E15 (see Discussion), with E12-E13 being the optimal time for dissociation and examination of cells from this region of the CNS.

The samples from spinal cords at different ages displayed a feature not found in samples from any of the supraspinal regions examined. As shown in Figure 13, the positions of both peak II and peak III were progressively shifted to lower values of light scatter in samples from progressively older animals. In all samples, it was still the case that the cells in peak II were labeled by PI and that almost all the cells in peak III excluded PI. The causc of this shift along the axis of light scatter is not known. No significant shifts were observed in the samples from other regions of the CNS (see below).

The light-scatter pattern characteristic of material dissociated from the embryonic mouse spinal cord was also seen with suspensions derived from embryonic rats of equivalent developmental stages (not shown). Cells dissociated without enzymes generated three peaks in light scatter, with the cells in peak II preferentially labeled by PI, while cells dissociated with trypsin generated peaks I and III only. 
Table 3. Comparison of methods for dissociating variable cells from the embryonic spinal cord of the mouse

\begin{tabular}{lllll}
$\begin{array}{l}\text { Method of } \\
\text { dissociation }\end{array}$ & $\begin{array}{l}\text { Number } \\
\text { of cells }\end{array}$ & $\begin{array}{l}\text { Trypan } \\
\text { blue ex- } \\
\text { clusion } \\
(\%)\end{array}$ & $\begin{array}{l}\text { FACS: } \\
\text { PI ex- } \\
\text { clusion } \\
(\%)\end{array}$ & $\begin{array}{l}\text { Total } \\
\text { yield } \\
\text { live cells }\end{array}$ \\
\hline No enzymes & $1.0 \times 10^{7}$ & 30 & 29 & $3.3 \times 10^{6}$ \\
Trypsin & $1.1 \times 10^{7}$ & 72 & 81 & $8.0 \times 10^{6}$ \\
Trypsin + SBTI & $1.1 \times 10^{7}$ & 52 & 33 & $5.2 \times 10^{6}$ \\
Chymotrypsin & $1.2 \times 10^{7}$ & 58 & 68 & $7.0 \times 10^{6}$ \\
Collagenase & $1.0 \times 10^{7}$ & 70 & 90 & $6.8 \times 10^{6}$ \\
Dispase & $0.7 \times 10^{7}$ & 89 & 97 & $6.3 \times 10^{6}$
\end{tabular}

Each sample was prepared from the spinal cords of 5 animals at E13; that is, all samples were prepared from approximately the same wet weight of tissue. Conditions for dissociation are described in Materials and Methods.

Number of cells refers to the combined total number of cells, both those that excluded trypan blue and thosc that took up the dyc. Total yield of live cells refers to the total number of cells that excluded the dye. FACS: PI exclusion refers to the number of cells that were found by analysis on the cell sorter not to be stained by PI expressed as a percentage of the combined total of cells in peaks II and III of light scatter.

Correlation between trypan blue staining and PI labeling was significant $(r=0.943$, $p<0.01)$ by Spcarman nonparametric correlation test.

\section{Dorsal root ganglia}

In early experiments (not illustrated), samples were prepared from spinal cords that had sensory (dorsal root) ganglia atlached. Spinal cords and dorsal root ganglia from animals ranging from E11 through E1 5 were separated, dissociated, and compared by analysis on the cell sorter. The two groups of cells could not be distinguished by light scatter at any of the ages examined; i.e., the positions of peaks in the histogram for light scatter were close and the distributions of the peaks were largely overlapping (not shown).

\section{Cells from supraspinal regions of the CNS}

\section{Hippocampus}

Cells from the developing hippocampus in mice at ages E16 through postnatal day $2(\mathrm{P} 2)$ were dissociated and analyzed on the cell sorter. Live cells could be dissociated at all ages examined, with a maximum yield of cells at approximately E18 (Fig. 14). As with the spinal cord, the yield of live cells was much higher in samples dissociated with trypsin than in those dissociated nonenzymatically. Unlike samples from the spinal cord, the positions of peaks II and III changed little between samples from animals of different ages.

\section{Hypothalamus}

The yield of live, dissociated cells from the hypothalamus was relatively low compared with the other regions examined. Cells could be recovered by nonenzymatic dissociation from E16 through E20 (Fig. 15), but all samples contained many dead cells. Few live cells were recovered by nonenzymatic dissociation at P2. As with other regions of the embryonic CNS, the yield of live cells was higher when trypsin was used in the dissociation, and the use of trypsin allowed recovery of viable cells at later stages of development (see E20 and P2 in Fig. 15). However, at most ages examined, large numbers of cells were killed even when trypsin was used in the dissociation. The best recovery of live cells was from animals at approximately E16.

\section{Cerebral cortex}

Cells were dissociated from the cerebral cortex in mice ranging from E13 through P4. The yield of viable cells was high from E13 through E20 (Fig. 16). Nonenzymatic dissociation produced
Table 4. Binding of cell-surface labels to dissociated cells from embryonic spinal cord

\begin{tabular}{llc} 
Sample & Ligand & $\begin{array}{l}\text { Live cells } \\
\text { fluorescent } \\
(\%)\end{array}$ \\
\hline Preparation 1 & A2B5 antibody & 86.7 \\
& Anti-Thy 1.2 & 1.7 \\
& Control & 1.2 \\
& Cholera toxin B & 97.0 \\
Control & 0.7 \\
& Concanavalin A & 79.5 \\
Wheat germ & 87.5 \\
$\quad$ agglutinin & 78.1 \\
Ricin & 2.4 \\
& Control & 33.8 \\
& A2B5 antibody & 58.2 \\
Preparation 2 & antitoxin & \\
& Antitoxin alone & 2.8 \\
& Anti-Thy 1.2 & 2.1 \\
Control & 2.0 \\
& Cholera toxin B & 36.9 \\
Control & 1.0
\end{tabular}

Cells for both preparations 1 and 2 were dissociated without added enzymes from spinal cords of mice at E12-E13. Analysis included only those cells that excluded PI and displayed values of light scatter higher than peak I; these were judged to be live cells on the basis of previously shown results (see above). The fraction of these cells that displayed fluorescence more intense than an arbitrarily chosen threshold is expressed as the percentage of live cells that were fluorescent.

Procedure for labeling is described in Materials and Methods. Control for FITCconjugated cholera toxin was untreated cells. Control for antibodies was FITCconjugated secondary antibody alone or an irrelevant primary antibody (not shown). Control for biotin-conjugated lectins was FITC-conjugated avidin only.

Results for preparation 1 are displayed in Figures 18, 19, and 21. Results for tetanus toxin-fragment $C$ labeling of preparation 2 are shown in Figure 20.

cell suspensions in which an unusually high fraction of the cells were vital, but dissociation with trypsin increased even this pcrcentage and allowed production of a sample with nearly all live cells (Fig. 16). At ages later than E20, however, recovery of viable cells decreased, and by P4 many fewer were obtained with either method of dissociation.

\section{Cerebellum}

Live cells could be dissociated from the cerebellum from E16, the earliest age examined, through at least P7 (not shown). As with the other regions examined, the total yield of live cells and the fraction of cells that were viable were both increased by the use of trypsin during dissociation (Fig. 17). Thus, substantial numbers of live cells could be recovered from the cerebellum throughout a long period of development.

\section{Antigens and binding sites on dissociated embryonic cells}

Cells dissociated from the spinal cords of mice at E13 include immature neurons, astrocytes, oligodendrocytes, and precursors to these, as shown by the survival of immunologically identified cells of all these types in culture (P. A. St. John and M. T. Caserta, unpublished observations). Because live cells could be dissociated from the spinal cord or from supraspinal regions only at relatively early stages of development. it was important to determine whether cells at these immature stages had yet developed cell-surface antigens and binding sites that could be used for the labeling and sorting of different cell types. This 

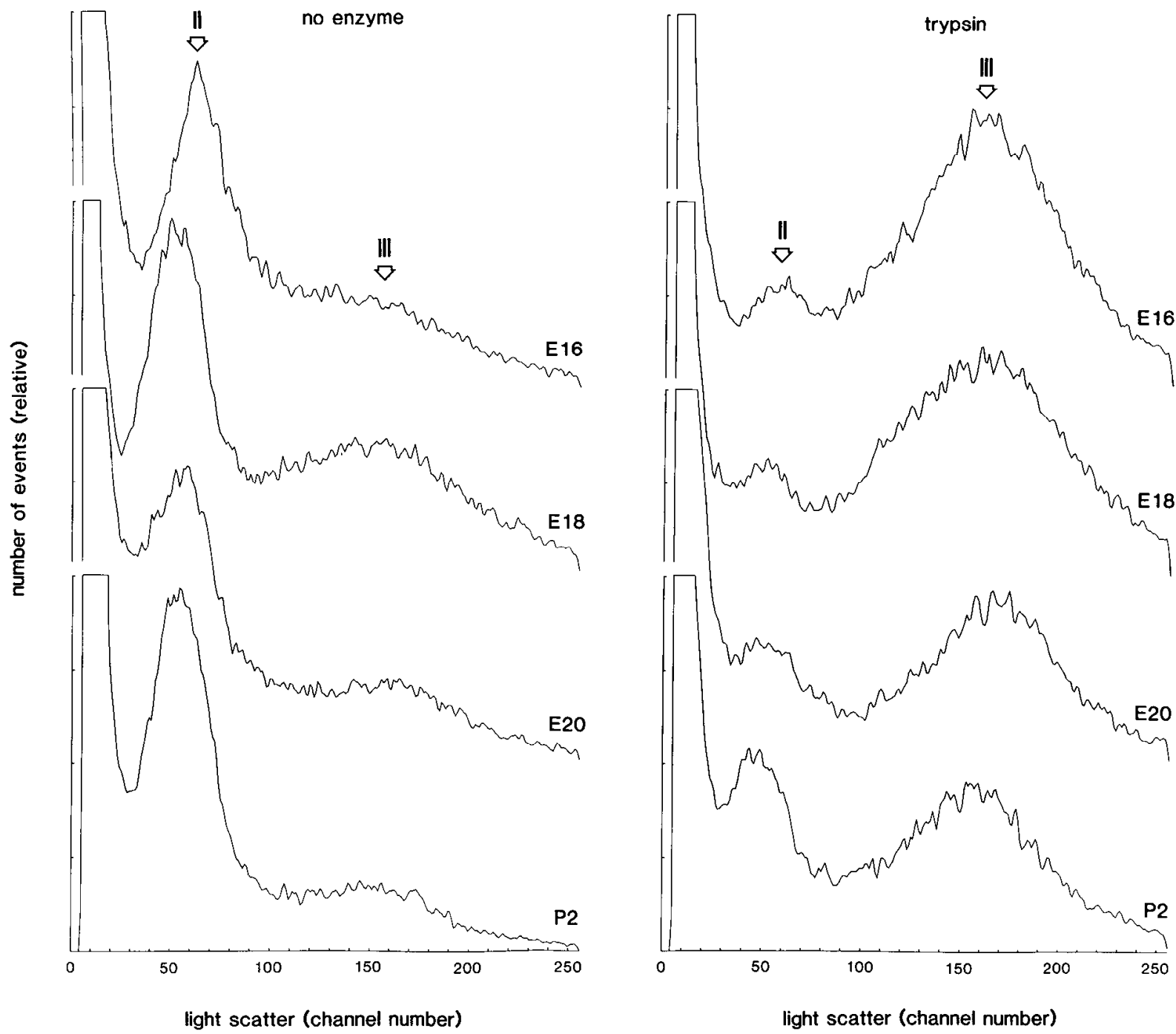

Figure 14. FACS analysis of material dissociated from the hippocampus in mice at E16, E18, E20, and P2. The left and right halves of the hippocampus were separated in individual animals at the indicated ages, and half were dissociated with trypsin and the other half without enzymes. The samples were stained with PI before analysis on the cell sorter. Histograms for light scatter alone are displayed. Note change in relative sizes, but little or no change in positions, of peaks II and III at different ages. Staining with PI (not shown) confirmcd that pcak II containcd the PIpositive cells in all samples.

question was addressed with cells from the E13 spinal cord and a series of antibodies, toxins, and lectins that bind to surfaces of cells from the mammalian CNS.

\section{Monoclonal antibody $A 2 B 5$}

Monoclonal antibody A2B5 (Eisenbarth et al., 1979) binds to the surfaces of most or all ncurons in the CNS (see Discussion). Analysis on the cell sorter showed that A2B5 bound to many of the live cells dissociated from the spinal cord at E13 (Fig. 18, Table 4). As shown in Fig. 18, the intensity of labeling ranged from levels barely above those of control samples to levels that were quitc high. However, there was no indication of the presence of subpopulations among the labeled cells on the basis of the intensity of labeling. Although A2B5 can be cytotoxic (Eisenbarth et al., 1979), the exclusion of PI from cells labeled by the antibody showed there was no detectable toxicity under the conditions used. In fact, in some samples there appeared to be a preferential labeling of live cells, in peak III of light scatter, and subcellular fragments, in peak $I$, rather than dead cells, in peak II (Fig. 18). The reason for this differential labeling was not determined.
Thy 1

In contrast to A2B5, antibody to the Thy 1 antigen, which also is present on many neurons in the adult mammalian CNS (Barclay, 1979; Barclay and Hyden, 1978; Mirsky and Thompson, 1975; Moore et al., 1971; Raff et al., 1979), showed no detectable binding to freshly dissociated cells from the spinal cord at E13 (Fig. 18). Separate experiments with cultured cells from the spinal cord and with frozen sections of older embryos (P. A. St. John, unpublished observations) showed that immunologically detectable Thy 1 antigen appeared several days later in development, consistent with the results of Zwerner et al. (1977), Barclay (1979), Fields et al. (1982), and Brown et al. (1984). However, this was at a time when few, if any, viable cells could be recovered from the spinal cord (see above).

\section{Toxins}

Tetanus toxin binds to gangliosides $G_{D 1}$ and $G_{T 1}$ (Dimpfel et al., 1977) and cholera toxin binds to ganglioside $G_{M 1}$ (e.g., Willinger and Schachner, 1980) on cell surfaces. Each toxin labels neurons in the adult CNS (Dimpfel et al., 1975; Koulakoff 

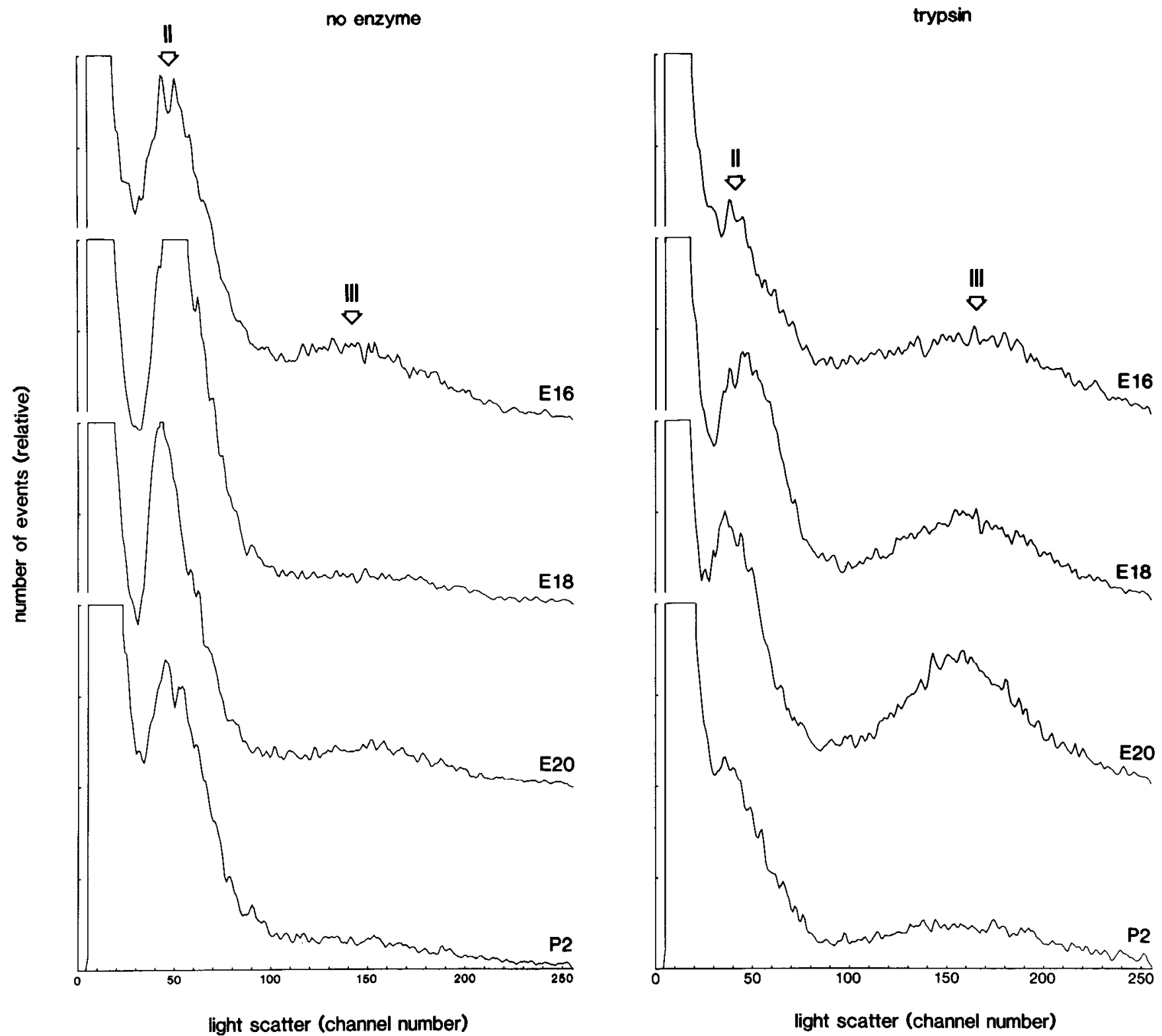

Figure 15. FACS analysis of material dissociated from the hypothalamus in mice at E16, E18, E20, and P2. The left and right halves of the hypothalamus were separated in individual animals at the indicated ages, and half were dissociated with trypsin and the other half without enzymes. The samples were stained with PI before analysis on the cell sorter. Histograms for light scatter alone are displayed. Note change in relative sizes, but little or no change in positions, of peaks II and III at different ages. Staining with PI (not shown) confirmed that peak II contained the PIpositive cells in all samples.

et al., 1982; Mirsky et al., 1978; Raff et al., 1979; Willinger and Schachner, 1980; also see discussion of specificity below). Analysis of dissociated cells from the spinal cord showed that many cells already had developed binding sites for each of these toxins by E13 (Table 4, Figs. 19 and 20). Like the binding of antibody A2B5, the binding of both tetanus toxin/antitoxin and of cholera toxin spanned a wide range of intensities, with no indication of subpopulations among the labeled cells in either case. Cholera toxin, like A2B5, appeared to bind preferentially to live cells and debris rather than to dead cells (Fig. 20).

\section{Ligands for undefined binding sites}

Lectins also were found to label groups of dissociated cells from the spinal cords of embryonic mice. Concanavalin A, wheat germ agglutinin (WGA), and Ricinus communis agglutinin I (RCA I) bound to many of these cells (Fig. 21, Table 4). The effect of lectin binding on the cells depended on the concentra- tion of lectin. At relatively high concentrations, in the range of $50-100 \mu \mathrm{g} / \mathrm{ml}$, each cell suspension in which cells had bound lectin presented an unusual histogram of light scatter, with a much smaller peak III and larger peak II (not shown) than in histograms for either unreacted samples or samples incubated with lectins that did not bind to cells; this suggests that binding of the lectin had been cytotoxic. At concentrations in the range of $1-2 \mu \mathrm{g} / \mathrm{ml}$, the same lectins were found to bind to cells, but they caused little or no detectable cytotoxicity (Fig. 21), as shown by the continued exclusion of PI from labeled cells.

Subpopulations of cells from the embryonic spinal cord also could be labeled by several monoclonal antibodies to undefined cell-surface antigens. Monoclonal antibodies raised against spinal cords of embryonic rats (P. A. St. John and A. E. Schaffner, unpublished observations) or against neural tissues from adults of other species (P. A. St. John, A. E. Schaffner, G. D. Trisler, and M. Nirenberg, unpublished observations) labeled live, dis- 
no enzyme

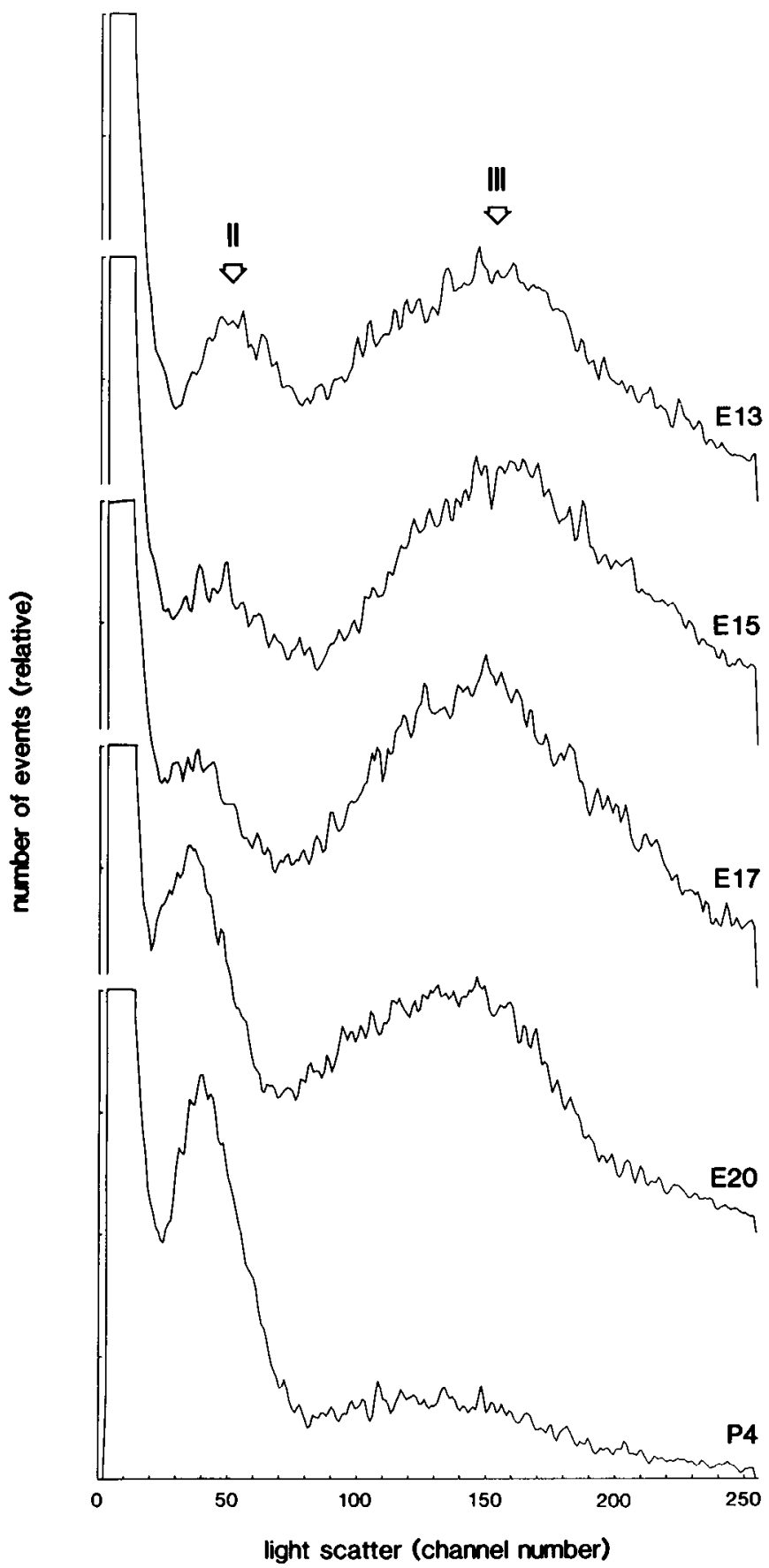

trypsin

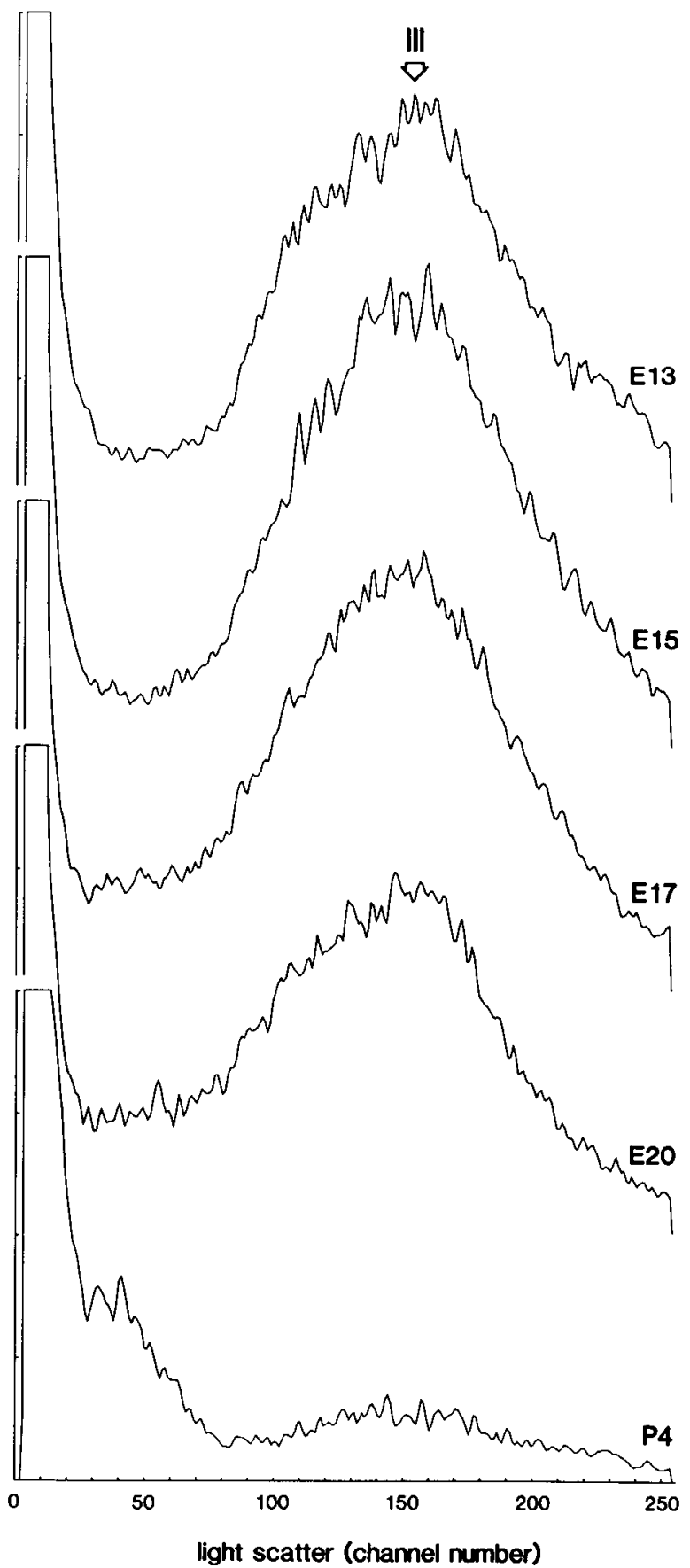

Figure 16. FACS analysis of material dissociated from the cerebral cortex in mice at E13, E15, E17, E20, and P4. Cortices from individual animals at the indicated ages were separated: one was dissociated with trypsin and the other without enzymes. The samples were stained with PI before analysis on the cell sorter. Histograms for light scatter alone are displayed. Note change in relative sizes, but little or no change in positions, of peaks II and III at different ages. Staining with PI (not shown) confirmed that peak II contained the PI-positive cells in all samples.

sociated cells at approximately E13, when these cells are suitable for analysis and isolation by cell sorting.

\section{Discussion}

These results demonstrate that tissue from the embryonic mammalian CNS can be dissociated into suspensions of viable cells suitable for analysis on a FACS and subsequent long-term maintenance in culture. Cell sorting has been used in previous studies of cells from the nervous system for analysis and isolation of neurons from the embryonic chick (Brackenbury et al., 1984;
Calof and Reichardt, 1984; Derby et al., 1983; Dyer et al., 1983; McPheeters and Okun, 1980; Rathjen and Gierer, 1981; Rathjen et al., 1981), and non-neuronal cells from neonatal and adult mice and rats (Abney et al., 1983; Campbell et al., 1977; Meyer et al., 1980). However, few studies of mammalian neurons have been reported. Sack et al. (1983) used a cell sorter for quantitative analysis of lectin binding to dissociated neurons from neonatal mouse cerebellum. A report of the isolation of putative motoneurons from spinal cords of adult mice (Eagleson and Bennett, 1983) provided little evidence for the viability of the 

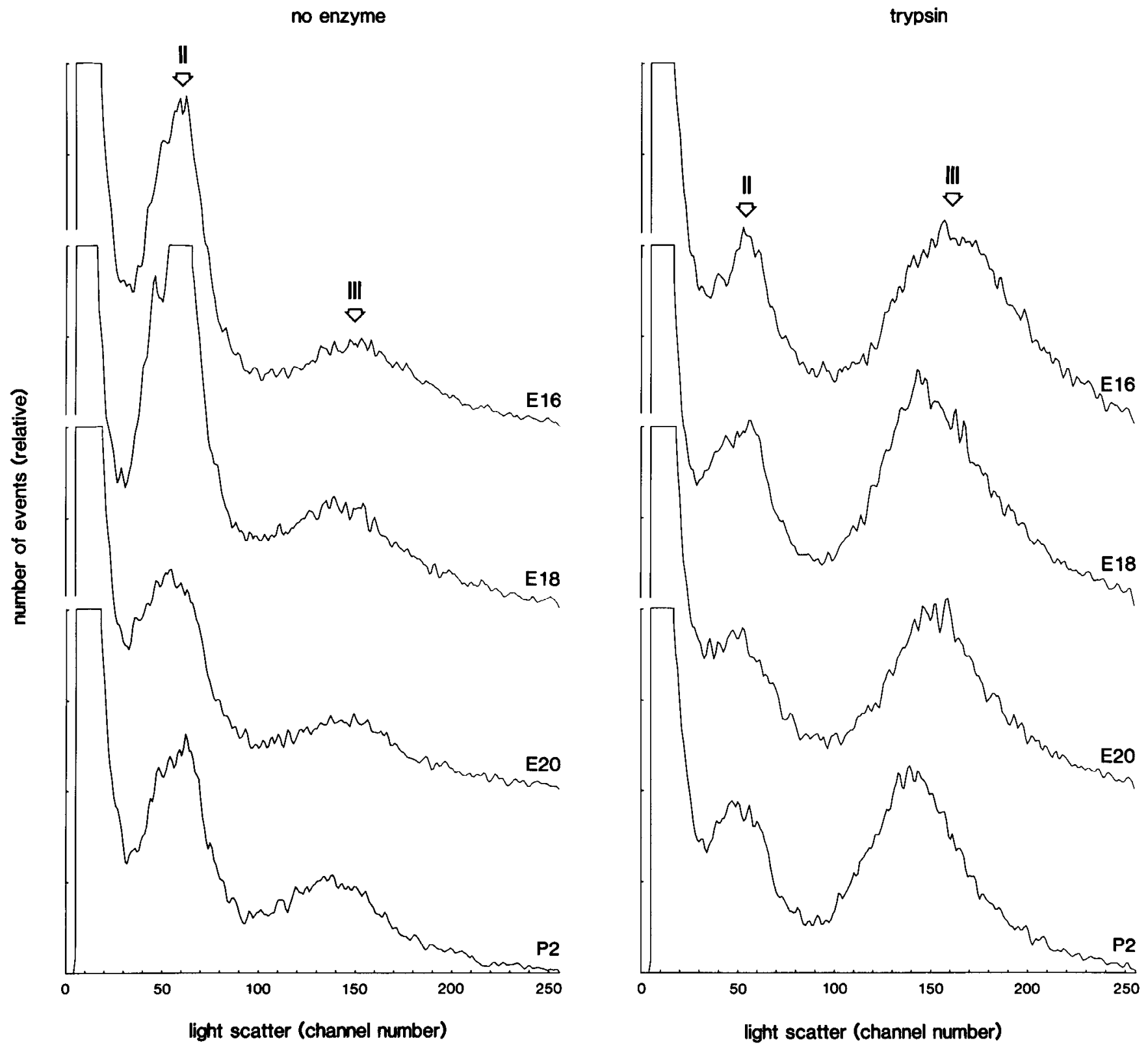

Figure 17. FACS analysis of material dissociated from the cerebellum in mice at E16, E18, E20, and P2. The left and right halves of the cerebellum were separated in individual animals at the indicated ages: one half was dissociated with trypsin and the other without enzymes. The samples were stained with PI before analysis on the cell sorter. Histograms for light scatter alone are displayed. Note change in relative sizes, but little or no change in positions, of the major peaks (II and III) at different ages. Staining with PI (not shown) confirmed that peak II contained the PI-positive cells in all samples.

sorted cells (see below). The present results provide an initial ccll-sorter analysis of cells dissociated from the spinal cord, dorsal root ganglia, hippocampus, hypothalamus, cerebellum, and cerebral cortex of the mouse. The results can be grouped into five areas of analysis: the use of a cell sorter to discriminate between live and dead cells dissociated from the embryonic mammalian CNS; the postsorting analysis of the viability of sorted cells; the dissociation of live cells from different regions of the CNS; the dependence on developmental stage for dissociation of live cells; and the use of the cell sorter to detect the binding of a panel of cell-surface ligands for cells of neural origin.

The live cells, dead cells, and subcellular fragments in these cell suspensions could be identified on the cell sorter on the basis of forward-angle light scatter. Dead cells appeared flat, collapsed, and phase-dark under microscopic examination. They scattered relatively little light, due to the loss of cellular volume.
Live cells, however, were spherical and phase-bright in microscopic appearance and generated relatively high levels of scattered light in the cell sorter. Subcellular fragments, generally small and phase-dark, scattered the least light on the cell sorter. Studies of cells from peripheral blood have shown that in some cases light scatter discriminates between live and dead cells, while in other cases it distinguishes among live cells of different sizes (e.g., see reviews by Loken and Stall, 1982; Loken et al., 1979). In the present work, forward-angle light scatter clearly distinguished between live and dead cells.

Viable and nonviable cells could be differentially labeled by the fluorescent dyes PI, EB, and AO. Propidium iodide appeared to be equivalent to trypan blue for labeling dead cells. Both PI and EB permeate dead cells and make them highly fluorescent but do not permeate live cells (Jacobs and Pipho, 1983; Krishan, 1975; Loken and Stall, 1982; Parks et al., 1979). Conversely, 


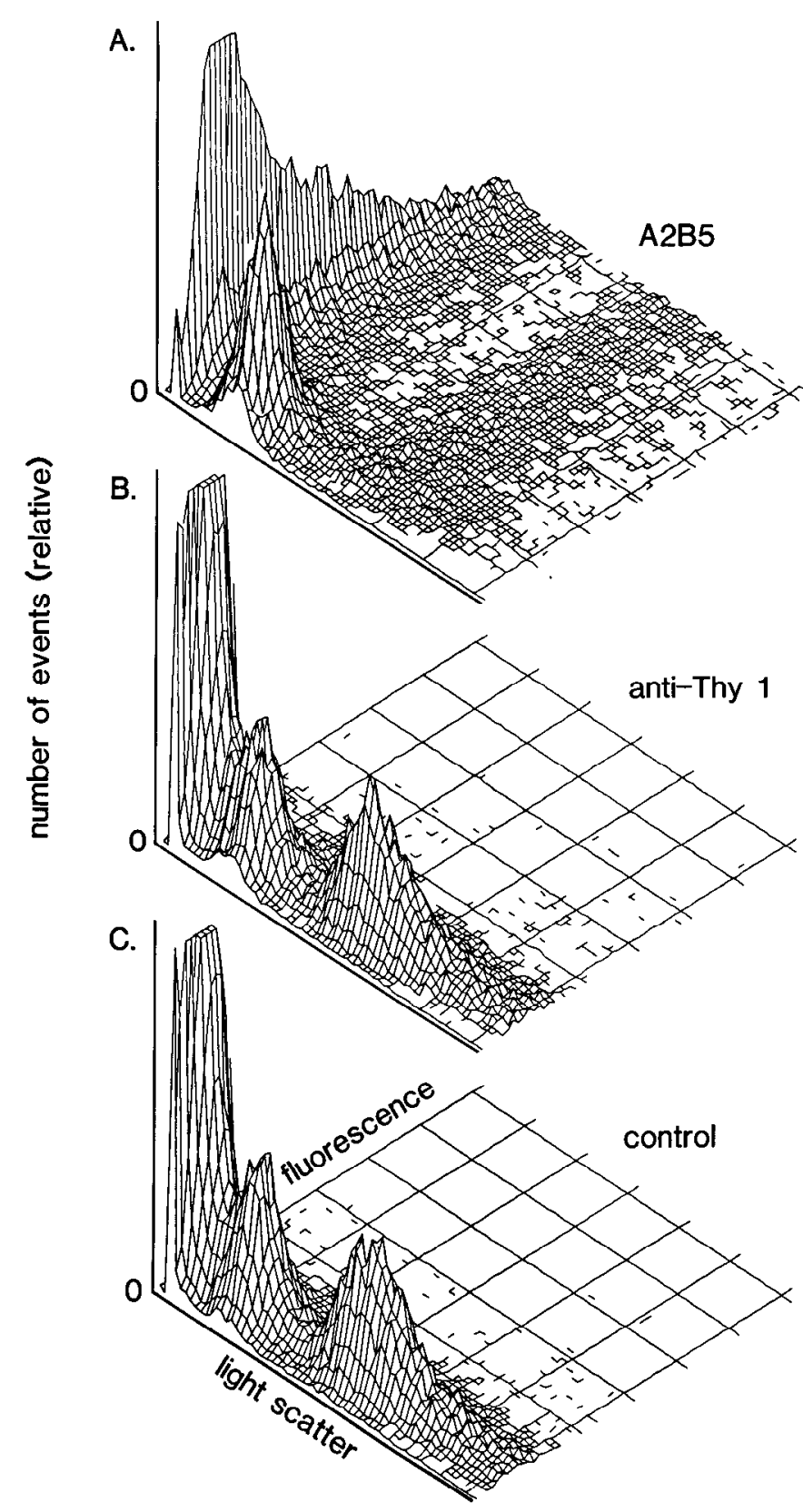

Figure 18. FACS analysis of monoclonal antibodies against neural cell-surface antigens binding to material dissociated from the mouse spinal cord at E13. Dual-parameter histograms of light scatter and fluorescence are shown. Cells dissociated without enzymes were labeled with $(A)$ antibody $\mathrm{A} 2 \mathrm{~B} 5,(B)$ antibody to Thy 1.2 antigen, or $(C)$ no antibody as described in Materials and Methods. Quantitative analysis of these results is presented in Table 4 (preparation 1). Linear scale on vertical axis.

AO labels live cells and not dead cells (Parks et al., 1979). Labeling dissociated cells from the CNS with these dyes confirmed that the live and dead cells in these samples could be clearly distinguished by FACS analysis.

Comparison of samples before and after sorting demonstrated that the live cells in a sample could be isolated by sorting with only minimal loss of viability. Analysis of survival in culture after sorting demonstrated long-term survival and differentiation of presumptive neurons and glial cells sorted from the embryonic CNS.

Because variability between replicate cell suspensions was low, the cell sorter could be used for quantitative comparisons

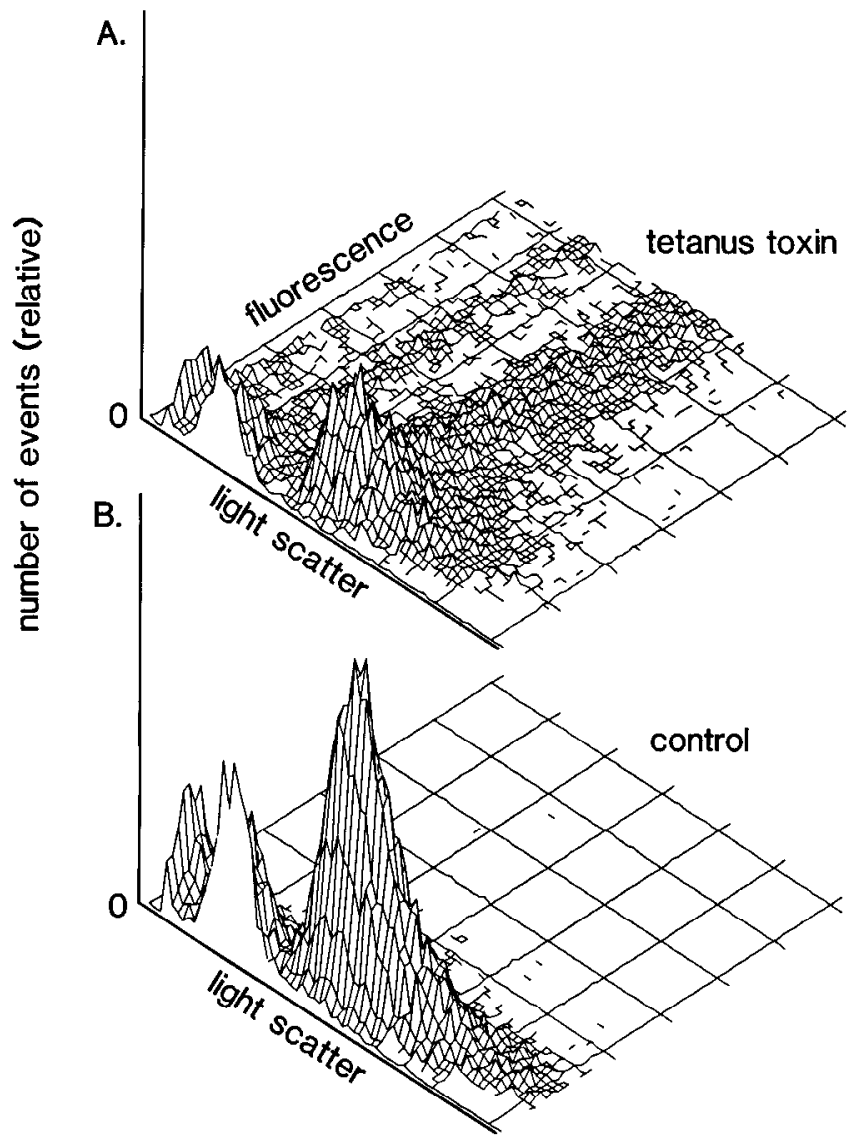

Figure 19. FACS analysis of tetanus toxin binding to material dissociated from the mouse spinal cord at E13. Figure shows dual-parameter histograms of light scatter and fluorescence. Cells dissociated without enzymes were labeled with $(A)$ tetanus toxin fragment $\mathrm{C}$ followed by monoclonal antibody to tetanus toxin or $(B)$ antibody to tetanus toxin alone. Quantitative analysis of these results is presented in Table 4 (preparation 2).

between different samples. Comparison of samples prepared by different methods of dissociation indicated that trypsin produces the optimal recovery of live cells. This finding is consistent with long-standing observations primarily based on exclusion of trypan blue from dissociated cells prepared for culture. However, one goal of the present line of experiments is to identify and isolate various cell types by labeling cell-surface determinants, and many of these might be removed by proteolytic enzymes. Thus, it is significant that large numbers of live cells could also be dissociated without enzymes.

Examination of samples prepared from embryos and neonatal animals of different ages showed that live cells could be recovered from each of the regions studied at a range of developmental stages. The optimal age and the range of ages for recovery of live cells were different for different regions. However, comparison of these results with studies of neurogenesis and histogenesis in various regions of the CNS of the mouse indicates that live cells can be dissociated from each of the regions examined here through a developmental period that includes the last mitoses, migrations, and early stages of differentiation of most or all classes of neurons and glial cells of that region.

Live cells can be dissociated from the spinal cord of the mouse from E10 through E15. This period includes the time of neurogenesis for almost all neurons and glial cells in the spinal cord (Altman and Bayer, 1984; Nornes and Carry, 1978; Sims and Vaughn, 1979), as well as the early stages of process outgrowth and synaptogenesis by the neurons (Flanagan, 1969; Holley et 


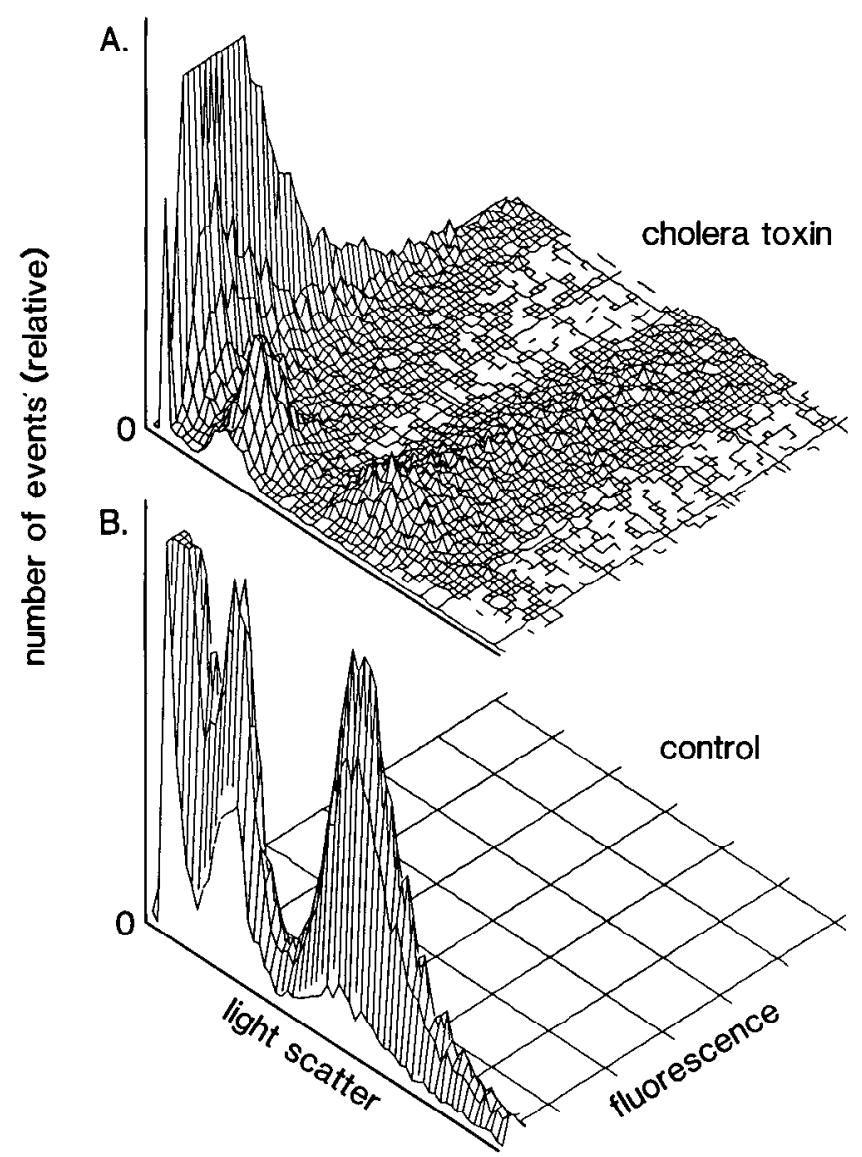

Figure 20. FACS analysis of cholera toxin subunit B binding to material dissociated from the mouse spinal cord at E13. Figure shows dualparameter histograms of light scatter and fluorescence. Cells dissociated without enzymes were labeled with $(A)$ FITC-conjugated subunit $\mathrm{B}$ of cholera toxin or $(B)$ buffer alone. Quantitative analysis of these results is presented in Table 4 (preparation 1).

al., 1982a-c; Lance-Jones, 1982; Wentworth, 1984a, b). Thus, most or all cell types in the spinal cord should be tractablc to analysis or isolation by cell sorting from the earliest developmental stages. However, few if any viable cells could be recovered from the spinal cords of early neonatal or adult mice by the methods used here. This finding may explain the apparently low yield of viable cells among the prcsumptive motoneurons isolated from adult mice by cell sorting (Eagleson and Bennett, 1983).

Live cells could be obtained from the hippocampus at least from E16 through P2, a period that includes most of the neurogenesis and early formation of the hippocampus (Angevine, 1965). Thus, it may be possible to use this technique to analyze and isolate pyramidal cells, granule cells, and interneurons from the hippocampus.

Dissociation of the hypothalamus produced a relatively low proportion of viablc cells in comparison with the other regions examined. Nevertheless, viable cells could be recovered at a range of developmental stages. Even the earliest stage examined here (E16) is past the time of neurogenesis and migration for most or all cells in the hypothalamus (Shimada and Nakamura, 1973). Thus, all the cell types of this region may be available for analysis by cell sorting.

The cerebral cortex of the mouse could be dissociated to produce samples highly enriched in viable cells at ages ranging from E13 through P2. This period includes the last periods of neurogenesis and the major periods of migration of neurons to form the cortex (Angevine and Sidman, 1961). Thus, the cerebral cortex may be a particularly fruitful source of viable

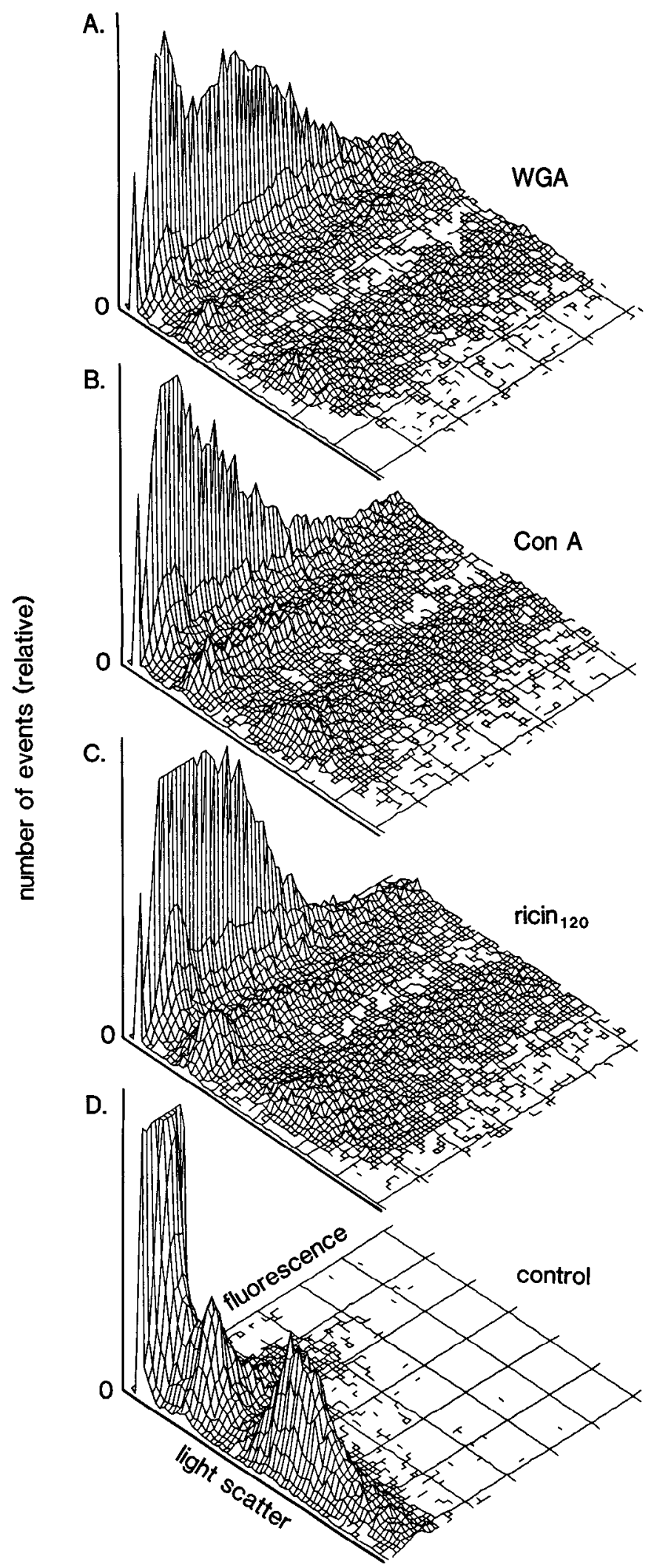

Figure 21. FACS analysis of lectin binding to material dissociated from the mouse spinal cord at E13. Figure shows dual-parameter histograms of light scatter and fluorescence. Cells dissociated without enzymes were labeled with $1-2 \mu \mathrm{g} / \mathrm{ml}$ of biotinylated $(A)$ wheat germ agglutinin (WGA), (B) concanavalin $\mathrm{A}($ Con $A),(C)$ Ricinus communis agglutinin I (ricin 120 ), or $(D)$ buffer alone, and followed by fluorescent avidin. Quantitative analysis of these results is presented in Table 4 (preparation 1). 
neurons of different types for analysis and isolation by cell sorting.

Viable cells were recovered from the cerebellum at ages from E16 through P2. A report by Sack et al. (1983) included FACS analysis of cerebellar cells from mice at P6. The present results extend those findings by directly analyzing the viability of cells recovered at a wide range of ages. The present results span a period that includes the neurogenesis and early differentiation of all the major types of neurons in the cerebellum (Miale and Sidman, 1961).

One unexplained observation was the shift in the positions of peaks II and III of light scatter in samples from the spinal cords of progressively older embryos. It is possible that the differences in light scatter reflected differences in the sizes of the live cells dissociated from embryos of different ages, with only smaller cells surviving dissociation from older embryos. Consistent with such an explanation would be the increasing number of glial cells in the spinal cord over the ages in question (Altman and Bayer, 1984; Sims and Vaughn, 1979; Wentworth, 1984a, b), if glial cells scattered less light than neurons in the cell sorter. However, the concomitant shift in peak II argues against such a simple explanation, as does the absence of a similar shift among samples from other regions of the CNS, in all of which glial cells generally develop later than neurons. Additional experiments, including a direct comparison of cells from E11 and E1 5 spinal cords, will be required to determine the cause of this shift.

Isolation of different cell types by cell sorting ultimately will require that different cell types can be identified with fluorescent labels at stages of development when the cells can survive dissociation from the intact CNS. In previous studies of both neural cells and cells from other tissues, a variety of toxins, lectins, and antibodies has been found useful for such labeling. In many cases, however, the utility of these ligands has been demonstrated only on mature, differentiated cells. The present results indicate that ligands from each of these classes also can be used to label embryonic cells.

Cells from the embryonic spinal cord of the mouse at E13 appear already to have developed binding sites for several ligands. Of particular interest are tetanus toxin, monoclonal antibody A2B5, and cholera toxin, because each of these binds predominantly to ncurons in the mammalian CNS (Dimpfel et al., 1975; Eisenbarth et al., 1979; Koulakoff et al., 1982; Mirsky et al., 1978; Raff et al., 1979; Schnitzer and Schachner, 1982; Willinger and Schachner, 1980). Each of these ligands bound to many or most of the live cells dissociated from the embryonic spinal cord. This would suggest that a large fraction of the live dissociated cells from the spinal cord at E13 are neurons. This interpretation is complicated by the observation that each of these ligands also binds to certain non-neuronal cells.

The binding of tetanus toxin may be the most specifically limited to neurons (e.g., Raff et al., 1979). Although tetanus toxin also binds to a class of glial cells and precursors in rat brain and optic nerve (Abney et al., 1983) and in mouse cerebellum (Schnitzer et al., 1984), there appears to be little binding to glial cells from mouse spinal cord in culture (P. A. St. John, unpublished observations). Additional experiments are needed to establish its specificity on freshly dissociated cells from the spinal cord. Antibody A2B5 appears less specific than tetanus toxin, binding to neurons, to subpopulations of astrocytes and oligodendrocytes from mouse spinal cord (Schnitzer and Schachner, 1982; P. A. St. John, unpublished observations), and to a class of astrocytes from rat brain and optic nerve (Abney et al., 1983). Cholera toxin binds to neurons, oligodendrocytes, and a subpopulation of astrocytes among neural cells from the rat CNS (Raff et al., 1979), and to neurons and glial cells in cultures from mouse cerebellum (Willinger and Schachner, 1980) and spinal cord (P. A. St. John, unpublished observations). Additional experiments using combinations of these and other la- bels will be required for precise quantification and isolation of the different cell types present in samples like these. In the present work, though, the cells were dissociated from spinal cords of animals at E13. This is after the last mitoses for almost all neurons and before a major wave of mitosis in glial cells (Altman and Bayer, 1984; Nornes and Carry, 1978; Sims and Vaughn, 1979). In combination with the results from labeling with tetanus toxin, cholera toxin, and A2B5, this suggests that the live cells from the spinal cord at E13 are predominantly neurons. It is of major significance for this line of investigation that such cell-surface markers are already present on cell surfaces at times when live cells suitable for cell sorting can be dissociated from the spinal cord.

The simplest explanation for the differences between preparations in the fraction of cells labeled by cell-surface probes (e.g., the two preparations included in Table 4) is that there were differences in the proportions of different cell types comprising the samples. It is also possible, though, that there were significant differences in the degree of expression of some surface markers even between animals that were relatively close in age, since there can be rapid developmental changes in the expression of certain markers (Koulakoff et al., 1982; P. A. St. John, unpublished observations). This will be examined in future experiments with carefully staged animals of different ages.

Cells from the mouse spinal cord at E13 also bind the lectins concanavalin A, WGA, and RCA I. Each lectin binds to a subpopulation of dissociated cells, as shown here, as well as to spinal cord cells in vivo and in vitro (P. A. St. John, unpublished observations). These results are similar to those of Sack et al. (1983) for dissociated cells from the cerebellum of the mouse. Sack et al. (1983) found a preferential binding of one lectin, RCA II, to large neurons from the cerebellum. Additional experiments are in progress to identify the types of spinal cord cells labeled by these lectins.

Thus, these results establish the feasibility of analyzing and isolating live mammalian neurons by fluorescence-activated cell sorting. This conclusion establishes the basis for future studies of identified types of mammalian neurons by cell sorting and long-term growth in culture.

\section{References}

Abney, E. R., B. P. Williams, and M. C. Raff (1983) Tracing the development of oligodendrocytes from precursor cells using monoclonal antibodies, fluorescence-activated cell sorting, and cell culture. Dev. Biol. 100: 166-171.

Altman, J., and S. A. Bayer (1984) The Development of the Rat Spinal Cord, Springer-Verlag, New York.

Angevine, J. B. (1965) Time of neuron origin in the hippocampal region. An autoradiographic study in the mouse. Exp. Neurol. Suppl. 2: $1-70$.

Angevine, J. B., and R. L. Sidman (1961) Autoradiographic study of cell migration during histogenesis of cerebral cortex in the mouse. Nature 192: 766-768.

Barclay, A. N. (1979) Localization of the Thy-1 antigen in the cerebellar cortex of rat brain by immunofluorescence during postnatal development. J. Neurochem. 32: 1249-1257.

Barclay, A. N., and H. Hyden (1978) Localization of the Thy-1 antigen in rat brain and spinal cord by immunofluorescence. J. Neurochem. 31: 1375-1391.

Barker, J. L., and B. R. Ransom (1978) Amino acid pharmacology of mammalian central neurones grown in tissue culture. J. Physiol. (Lond.) 280: 331-354.

Brackenbury, R., M. E. Greenberg, and G. M. Edelman (1984) Phenotypic changes and loss of N-CAM-mediated adhesion in transformed embryonic chicken retinal cells. J. Cell Biol. 99: 1944-1954.

Brown, R. H., J. Schweitzer, and M. A. Dichter (1984) Expression of the Thy-1 antigen in long-term cultures of embryonic mouse spinal cord. Brain Res. 296: 87-91.

Calof, A. L., and L. F. Reichardt (1984) Motoneurons purified by cell sorting respond to two distinct activities in myotube-conditioned medium. Dev. Biol. 106: 194-210.

Campbell, G. L., M. Schachner, and S. O. Sharrow (1977) Isolation 
of glial cell-enriched and -depleted populations from mouse cerebellum by density gradient centrifugation and electronic cell sorting. Brain Res. 127: 69-86.

Derby, M. A., S. A. Dyer, and L. Glaser (1983) Monoclonal antibodies against a differentiated retinal cell population. Brain Res. 283: $317-$ 325 .

Dimpfel, W., J. H. Neale, and E. Habermann (1975) ${ }^{125}$ I-labelled tetanus toxin as a neuronal marker in tissue cultures derived from embryonic central nervous system. Naunyn Schmiedebergs Arch. Pharmacol. 290: 329-333.

Dimpfel, W., R. T. C. Huang, and E. Habermann (1977) Gangliosides in nervous tissue cultures and binding of ${ }^{125}$ I-labelled tetanus toxin: A neuronal marker. J. Neurochem. 29: 329-334.

Dyer, S. A., M. A. Derby, G. J. Cole, and L. Glaser (1983) Identification of sub-populations of chick neural retina cells by monoclonal antibodies: A fluorescence activated cell sorter screening technique. Brain Res. 285: 197-203.

Eagleson, K. L., and M. R. Bennett (1983) Survival of purified motoneurones in vitro: Effects of skeletal muscle-conditioned medium. Neurosci. Lett. 39: 187-192.

Eisenbarth, G. S., F. S. Walsh, and M. Nirenberg (1979) Monoclonal antibody to a plasma membrane antigen of neurons. Proc. Natl. Acad. Sci. USA 76: 4913-4917.

Fields, K. L., D. N. Currie, and G. R. Dutton (1982) Development of Thy-1 antigen on cerebellar neurons in culture. J. Neurosci. 2:663673.

Flanagan, A. E. H. (1969) Differentiation and degeneration in the motor horn of the foetal mouse. J. Morphol. 129: 281-306.

Holley, J. A., C. C. Wimer, and J. E. Vaughn (1982a) Quantitative analyses of neuronal development in the lateral motor column of the mouse spinal cord. I. Genetically associated variations in somal growth patterns. J. Comp. Neurol. 207: 314-321.

Holley, J. A., C. C. Wimer, and J. E. Vaughn (1982b) Quantitative analyses of neuronal development in the lateral motor column of the mouse spinal cord. II. Development of motor neuronal organelles. J. Comp. Neurol. 207: 322-332.

Holley, J. A., C. C. Wimer, and J. E. Vaughn (1982c) Quantitative analyses of neuronal development in the lateral motor column of the mouse spinal cord. III. Generation and settling patterns of large and small neurons. J. Comp. Neurol. 207: 333-343.

Jacobs, D. B., and C. Pipho (1983) Use of propidium iodide staining and flow cytometry to measure antibody-mediated cytotoxicity: Resolution of complement-sensitive and resistant target cells. J. Immunol. Methods 62: 101-108.

Kimelberg, H. K. (1983) Primary astrocyte cultures - a key to astrocyte function. Cell. Mol. Neurobiol. 3: 1-16.

Koulakoff, A., B. Bizzini, and Y. Berwald-Netter (1982) A correlation between the appearance and the evolution of tetanus toxin binding cells and neurogenesis. Dev. Brain Res. 5: 139-147.

Krishan, A. (1975) Rapid flow cytofluorometric analysis of mammalian cell cycle by propidium iodide staining. J. Cell Biol. 66: 188193.

Kruth, H. S. (1982) Flow cytometry: Rapid biochemical analysis of single cells. Anal. Biochem. 125: 225-242.

Lance-Jones, C. (1982) Motoneuron cell death in the developing lumbar spinal cord of the mouse. Dev. Brain Res. 4: 473-479.

Loken, M. R., and A. M. Stall (1982) Flow cytometry as an analytical and preparative tool in immunology. J. Immunol. Methods 50: R85R112.

Loken, M. R., R. D. Stout, and L. A. Herzenberg (1979) Lymphoid cell analysis and sorting. In Flow Cytometry and Sorting, M. R. Melamed, P. F. Mullaney, and M. L. Mendelsohn, eds., pp. 505-528, Wiley, New York

McCarthy, K. K., and J. de Vellis (1980) Preparation of separate astroglial and oligodendroglial cultures from rat cerebral tissue. J. Cell Biol. 85: 890-902.

McPheeters, M., and L. M. Okun (1980) Identification and isolation in-vitro of presumptive motoneurons marked by retrograde transport of a new fluorescent tracer. Soc. Neurosci. Abstr. 6: 733.

Meyer, R. A., M. E. Zaruba, and G. M. McKann (1980) Flow cytometry of isolated cells from the brain. Anal. Quant. Cytol. 2: 66-74.

Miale, I. L., and R. L. Sidman (1961) An autoradiographic analysis of histogenesis in the mouse cerebellum. Exp. Neurol. 4: 277-296.

Mirsky, R. (1982) The use of antibodies to define and study major cell types in the central and peripheral nervous system. In Neuroimmunology, J. Brockes, ed., pp. 141-181, Plenum, New York
Mirsky, R., and E. J. Thompson (1975) Thy-1 (theta) antigen on the surface of morphologically distinct brain cell types. Cell 4:95-101.

Mirsky, R., L. M. B. Wendon, P. Black, C. Stolkin, and D. Bray (1978) Tetanus toxin: A cell surface marker for neurons in culture. Brain Res. 148: 251-259.

Moore, M. J., P. Dikkes, A. E. Reif, F. C. A. Romanul, and R. L. Sidman (1971) Localization of theta alloantigens in mouse brain by immunofluorescence and cytotoxic inhibition. Brain Res. 28: 283293.

Nornes, H. O., and M. Carry (1978) Neurogenesis in spinal cord of mouse: An autoradiographic analysis. Brain Res. 159: 1-16.

Parks, D. R., V. M. Bryan, V. T. Oi, and L. A. Herzenberg (1979) Antigen specific identification and cloning of hybridomas with a fluorescence-activated cell sorter (FACS). Proc. Natl. Acad. Sci. USA 76: 1962-1966.

Raff, M. C., K. L. Fields, S. Hakomori, R. Mirsky, R. M. Pruss, and J. Winter (1979) Cell-type specific markers for distinguishing and studying neurons and the major classes of glial cells in culture. Brain Res. 174: 283-308.

Raff, M. C., E. R. Abney, J. Cohen, R. Lindsay, and M. Noble (1983) Two types of astrocytes in cultures of developing rat white matler: Differences in morphology, surface gangliosides, and growth characteristics. J. Neurosci. 3: 1289-1300.

Ransom, B. R., E. Neale, M. Henkart, P. N. Bullock, and P. G. Nelson (1977) Mouse spinal cord in cell culture. I. Morphology and intrinsic neuronal electrophysiologic properties. J. Neurophysiol. 40: 11321150.

Rathjen, F, G., and A. Gierer (1981) Cholera-toxin binding to cells of developing chick retina analyzed by fluorescence-activated cell sorting. Brain Res. 227: 539-549.

Rathjen, F. G., B. Holcombe, and A. Gierer (1981) Separation of cell populations from embryonic chick neural retina with fluorescenceactivated cell sorting. J. Biochem. Biophys. Methods 4: 191-207.

Rugh, R. (1968) The Mouse, Burgess, Minneapolis.

Sack, H. J., M. Stohr, and M. Schachner (1983) Cell-type specific binding of Ricinus lectin to murine cerebellar cell surfaces in vitro. Cell Tissue Res. 228: 183-204.

St. John, P. A., and J. L. Barker (1983) Analysis and purification of neurons by immunofluorescence and fluorescence-activated cell sorting. Soc. Neurosci. Abstr. 9: 7.

Schachner, M. (1982) Cell type-specific surface antigens in the mammalian nervous system. J. Neurochem. 39: 1-8.

Schaffner, A. E., and R. L. Schnarr (1983) The isolation and purification of neurons from the vertebrate central nervous system. In Current Methods in Cellular Neurobiology, Vol. IV: Model Systems, J. L. Barker and J. F. McKelvy, eds., pp. 131-185, Wiley, New York. Scher, I., and M. G. Mage (1984) Cellular identification and separation. In Fundamental Immunology, W. E. Paul, ed., pp. 767-780, Raven, New York.

Schnitzer, J., and M. Schachner (1982) Cell type specificity of a neural cell surface antigen recognized by the monoclonal antibody A2B5. Cell Tissue Res. 224: 625-636.

Schnitzer, J., S. U. Kim, and M. Schachner (1984) Some immature tetanus toxin-positive cells share antigenic properties with subclasses of glial cells. An immunofluorescence study in the developing nervous system of the mouse using a new monoclonal antibody S1. Brain Res. 318: 203-217.

Shimada, M., and T. Nakamura (1973) Time of neuron origin in mouse hypothalamic nuclei. Exp. Neurol. 41: 163-173.

Sims, T. J., and J. E. Vaughn (1979) The generation of neurons involved in an early reflex pathway of embryonic mouse spinal cord. J. Comp. Neurol. 183: 707-720.

Wentworth, L. E. (1984a) The development of the cervical spinal cord of the mouse embryo. I. A Golgi analysis of ventral root neuron differentiation. J. Comp. Neurol. 222: 81-95.

Wentworth, L. E. (1984b) The development of the cervical spinal cord of the mouse embryo. II. A Golgi analysis of sensory, commissural, and association cell differentiation. J. Comp. Neurol. 222: 96-115.

Willinger, M., and M. Schachner (1980) GM1 ganglioside as a marker for neuronal differentiation in mouse cerebellum. Dev. Biol. 74: 101117.

Zwerner, R. K., R. T. Acton, and N. W. Seeds (1977) The developmental appearance of Thy- 1 in mouse reaggregating brain cell cultures. Dev. Biol. 60: 331-335. 